Supporting Information

\title{
Brain Accumulating Nanoparticles for Assisting Astrocytes to Reduce Human Immunodeficiency Virus and Drug Abuse-Induced Neuroinflammation and Oxidative Stress
}

Bapurao Surnar, ${ }^{a}$ Anuj S. Shah, ${ }^{a}$ Minseon Park, ${ }^{a}$ Akil A. Kalathil, ${ }^{a}$ Mohammad Z. Kamran, ${ }^{a}$ Royden Ramirez Jaime, ${ }^{b}$ Michal Toborek, ${ }^{a}$ Madhavan Nair, ${ }^{b}$ Nagesh Kolishetti, ${ }^{* b, c}$ Shanta Dhar ${ }^{\star a, d}$

${ }^{a}$ Department of Biochemistry and Molecular Biology, University of Miami Miller School of Medicine, Miami, FL 33136

${ }^{b}$ Department of Immunology and Nano-Medicine, Herbert Wertheim, College of Medicine, Florida International University, Miami, FL, 33199

'Institute of Neuroimmune Pharmacology, Herbert Wertheim College of Medicine, Miami, FL 33199

'Sylvester Comprehensive Cancer Center, Miller School of Medicine, University of Miami, Miami, FL 33136

${ }^{*}$ To whom correspondence should be addressed.

Email: nkolishe@fiu.edu

Email: shantadhar@med.miami.edu 
Materials: All chemicals were used without further purification unless otherwise noted. The polymer PLGA-b-PEG-TPP, 6-bromohexanoic acid, Oc-[G2]-(Asp) 4 were synthesized using previously published methods. ${ }^{1-2}$ Antiretroviral (ARV) drugs, saquinavir mesylate, atazanvir, tenofovir disproxil fumarate, indinavir sulfate salt hydrate, ritonavir, zidovudine, lopinavir, efavirenz, darunavir, nevirapine anhydrous, lamivudine, fosamprenavir calcium, amprenavir, dolutegravir, elvitegravir, cobicistat, abacavir sulfate, emtricitabine, raltegravir potassium, maraviroc, enfuvirtide acetate, delavirdine mesylate, bictegravir, didanosine, zalcitabine, and stavudine were purchased from Sigma, AmBeed, A ChemBlock, Selectchem, and CarboSynth. $\mathrm{CoQ}_{10}$ and 2',7'-dichlorofluorescin diacetate (DCFDA) was purchased from Sigma Aldrich. XFe96 FluxPaks (SKU 102416-100) were purchased from Agilent Seahorse. NucBlue $®$ live cell stain (Cat. No. R37605), CellLight ${ }^{\mathrm{TM}}$ mitochondria-GFP was purchased from thermos Fischer Scientifics. Astrocytes basal media and astrocytes SingleQuots ${ }^{\mathrm{TM}}$ Kit growth factors were purchased as a single kit (CC 3186) from Lonza. Pierce ${ }^{\circledR}$ Bicinchoninic acid (BCA) protein assay kit (Cat No. 23225) was procured from ThermoFisher Scientific. Regenerative cellulose membrane Amicon Ultra Centrifugal 100 kDa filters were purchased from Merck Millipore Ltd. Copper grids for transmission electron microscopy (TEM) were purchased from Electron Microscopy Sciences. TAT peptide (Cat. No. 2222) was procured from NIH. Human IL-1 $\beta$ (Cat. No. 557953), IL-6 (Cat. No. 555220) and TNF $\alpha$ (Cat. No. 555212) kits were purchased from BD Biosciences. Elisa kit for IL-2 (Cat no. 0801200) was purchased from ZeptoMetrix Corp. Methamphetamine (Cat. No. M8750) and cocaine (Cat. No. C5776) were purchased from Sigma Aldrich. The HIV Clade B (HIV-1 Ba-L, Cat. No. 510) viral particles were procured from NIH AIDS Reagent Program. Alanine transaminase colorimetric activity assay kit (Cat. No. 700260) was purchased from Cayman chemicals. Aspartate Aminotransferase Activity Assay Kit (Cat. No. 
Cat. No. MAK055-1KT) was purchased from Millipore Sigma. Strata- $X^{\mathrm{TM}}$ columns (8B-S100UBJ) were purchased from Phenomenex. Neurobasal media (cat \#12348017) was purchased from Thermo Fischer scientific along with supplements. DNase-I (cat \# 04536282001) was purchased from was purchased from Millipore Sigma. Poly-D-Lysine (cat \# A3890401) was purchased from ThermoFisher scientific. NeuN (ab177487), GFAP (ab4674), TMEM119 (ab209064), ICAM1 (ab179707), catalase (ab52477) primary antibodies were purchased from Abcam. MAP2 (D5G1) was purchased from Cell Signaling Technology. P24 primary antibody (ARP530) was procured from HIV reagent program. The secondary anti-chicken (ab6875), and anti-rabbit (ab150080) were purchased from Abcam. Goat anti-human secondary antibody (A11013) was purchased from Invitrogen. Elisa kits for IL1- $\beta$ (cat\# 559603) and TNF $\alpha$ (cat\#558534) were purchased from BD sciences. HIV-1 P24 antigen Elisa 2.0 kit (cat\# 0801002) was purchased from Zeptometrix. The chimeric HIV-NDK (abbreviated as EcoHIV) generously gifted by Dr. David Volsky, Icahn School of Medicine at Mount Sinai. A retroviral vector pBMNI-GFP procured from Addgene (plasmid \#1736).

Instruments: Nanopure water purification system (18.2 M $\Omega$, Millipore Milli-Q Biocel). Slide-ALyzer MINI dialysis tubes were obtained from Thermo Scientific. High-performance liquid chromatography (HPLC) experiments were conducted using an Agilent 1200 LC series instrument equipped with automated injector, and UV and fluorescence detectors. Dynamic light scattering (DLS) measurements were performed on a Malvern Zetasizer Nano ZS system. Cells were counted using a Countess $®$ automated cell counter (Invitrogen Life Technology). Plate reader analyses were performed on a Bio-Tek Synergy HT microplate reader. TEM images were acquired using a JEOL JEM-1400 equipped with a Gatan Orius SC 200D CCD digital camera. Mitochondrial bioenergetics assays were performed on XFe96 Extracellular Flux Analyzers 
(Agilent Seahorse Biosciences). Confocal microscopy images were obtained using an Olympus FluoView FV3000. Microglia cells were sorted using an LSR-Fortessa-HTS instrument at the core facility of University of Miami. Real-Time PCR (RT-PCR) studies were carried out using CFX Connect System from BIO-RAD. Reverse Transcription Supermix for RT-qPCR kit was obtained from Bio-Rad. Real time PCR reaction was carried out using SsoAdvanced Universal SYBR $\circledast$ Green Supermix in $20 \mu \mathrm{L}$ reaction. $\beta$-actin was used as an internal control. Data were analyzed according to the comparative $\mathrm{Ct}$ value and expressed as fold change 2- $\Delta \Delta \mathrm{CT}$. HIV was assessed using the following primers and probe: NDKgag_F 5'GACATAAGACAGGGACCAAAGG-3'; NDKgag_R 5'-CTGGGTTTGCATTTTGGACC-3'. The primer sequence for $\beta$-actin gene was: Forward 5'GCATCCTCACCCTGAAGTAC3' and reverse 5'GATAGCACAGCCTGGATAGC3'. GAPDH (4326317E), C3 (Mm00437859_g1) and OLFM1 (Mm00444666_m1) was purchased from Life Technologies. The primers for ROS marker purchased from Integrated DNA Technologies (IDT). The primer sequence for GCLC gene: Forward 5'ACACCTGGATGATGCCAACGAG3' and reverse 5'CCTCCATTGGTCGGAACTCTAC3'. The primer sequence for GCLM gene: Forward 5'TCCTGCTGTGTGATGCCACCAG3' and reverse 5'GCTTCCTGGAAACTTGCCTCAG3'. The primer sequence for GPX7 gene: Forward 5'CGACTTCAAGGCGGTCAACATC3' and reverse 5'AAGGCTCGGTAGTTCTGGTCTG3'.

Cells and Culture Condition: Human microglia cells (HMC3, CRL-3304) were purchased from ATCC and grown in Dulbecco's modified eagle's medium (DMEM) along with $10 \%$ fetal bovine serum (FBS). Cell cultures were maintained in a humidified cell culture incubator at $37^{\circ} \mathrm{C}$ and with $5 \% \mathrm{CO}_{2}$. Normal human astrocytes $(\mathrm{nHA})$ were purchased from Lonza (CC-2265). These cells were cultured in astrocyte basal media (ABM) supplemented with astrocytes SingleQuots ${ }^{\mathrm{TM}}$ 
Kit growth factors composed of FBA, L-glutamine, gentamycin, and ascorbic acid. Cell cultures were maintained in a humidified cell culture incubator at $37{ }^{\circ} \mathrm{C}$ and with $5 \% \mathrm{CO}_{2}$.

The isolated astrocytes were grown in glial media (Dulbecco's modified eagle's medium along with $10 \%$ fetal bovine serum (FBS). The isolated neuronal cells were grown in Neurobasal media with $10 \%$ FBS and $2 \%$ of B27 supplement. Cell cultures were maintained in a humidified cell culture incubator at $37^{\circ} \mathrm{C}$ and with $5 \% \mathrm{CO}_{2}$.

Nanoparticle Synthesis: A library of targeted NPs was first prepared for preliminary testing using $5 \mathrm{mg} / \mathrm{mL}$ of the targeted polymer PLGA- $b$-PEG-TPP, $10 \%$ TPP- $\left(\mathrm{CH}_{2}\right)_{5}-\mathrm{COOH}$ with respect to the polymer, and $10 \%$ of each ART (with respect to the polymer) taken from a $20 \mathrm{mg} / \mathrm{mL}$ stock solution in DMSO. The solutions were mixed in acetonitrile and made with a total volume of 1 $\mathrm{mL}$, and added slowly and dropwise to water being stirred at $900 \mathrm{rpm}$. The solution was stirred for $2 \mathrm{~h}$, then filtered using Amicon filtration (100 MWCO) at 2800 RPM. Initial DLS measurements of size and zeta potential were taken and the solutions were stored at $4{ }^{\circ} \mathrm{C}$. HPLC was used along with standards of the ARTs to see which of the ARTs showed signs of loading into the NPs. This was indicated by a presence of a peak occurring at the same elution time as the peaks for the ART standards. The HPLC elution time and $\lambda_{\max }$ values were noted for the nine drugs that showed signs of loading: saquinavir (16.8 $\mathrm{min}, 268 \mathrm{~nm}$ ), efavirenz (27.3 $\mathrm{min}, 268 \mathrm{~nm}$ ), darunavir (24.0 min, $268 \mathrm{~nm}$ ), dolutegravir (23.0 min, $268 \mathrm{~nm}$ ), elvitegravir (27.9 minutes, 268 $\mathrm{nm}$ ), raltegravir (22.8 $\mathrm{min}, 268 \mathrm{~nm}$ ), delavirdine (20.6 min, $268 \mathrm{~nm}$ ), bictegravir (23.3 min, 268 $\mathrm{nm})$, and stavudine (13.3 $\mathrm{min}, 268 \mathrm{~nm})$.

ART Feed Testing: For the ARTs that showed signs of loading, NPs were next prepared with varying feeds of the selected ARTs. NPs were prepared using $5 \mathrm{mg} / \mathrm{mL}$ of the targeted polymer PLGA- $b$-PEG-TPP, $10 \%$ TPP- $\left(\mathrm{CH}_{2}\right)_{5}-\mathrm{COOH}$, and ARTs at a feed of either $0.5 \mathrm{mg} / \mathrm{mL}(10 \%), 1$ 
$\mathrm{mg} / \mathrm{mL}(20 \%), 1.5 \mathrm{mg} / \mathrm{mL}$ (30\%), $2 \mathrm{mg} / \mathrm{mL}$ (40\%), or $2.5 \mathrm{mg} / \mathrm{mL}(50 \%)$. The NPs were produced and purified using the same process as above. HPLC was used to determine percent loading $(\% \mathrm{~L})$ and percent encapsulation efficiency (\%EE) for the various feeds of each ART into the targeted T-ART-NPs.

Release Studies: Release studies were conducted to test the release of ARTs loaded in the ART-NPs. $20 \mu \mathrm{L}$ of $5 \mathrm{mg} / \mathrm{mL}$ nanoparticle solution (in water) was diluted to $200 \mu \mathrm{L}$ using water. These solutions were then put into dialysis chambers and placed into phosphate buffered saline with $\mathrm{pH}$ 7.4. Samples were taken out at various time points up to $72 \mathrm{~h}$. The solution remaining in the dialysis chambers was diluted in acetonitrile, and HPLC was used to test the amount of drug remaining in the solution. The HPLC elution time and $\lambda_{\max }$ values were noted for the three drugs that showed good loading: efavirenz (27.3 min, $268 \mathrm{~nm})$, darunavir (24.0 min, $268 \mathrm{~nm}$ ), and elvitegravir (27.9 $\mathrm{min}, 268 \mathrm{~nm}$ ).

Cell Viability Assays: The cytotoxicity of Efavirenz, Elvitegravir, Darunavir, and their nanoformulations T-EFV-NP, T-EVG-NP, and T-DRV-NP were tested in microglia cells using the MTT assay. The cells were plated (3000 cells/well) in a 96-well plate and allowed to grow overnight. The media was changed and increasing concentrations of each article were added. The media was aspirated and fresh media was added and further incubated for an additional 48 h. After the given incubation time, $20 \mu \mathrm{L} /$ well MTT was added ( $5 \mathrm{mg} / \mathrm{mL}$ stock in PBS) and incubated for $5 \mathrm{~h}$ in order for MTT to be reduced to purple formazan. The media was removed and the cells were lysed with $100 \mu \mathrm{L}$ of DMSO. In order to homogenize the formazan solution, the plates were subjected to 10 min of gentle shaking and the absorbance was read at $550 \mathrm{~nm}$ with a background reading at $800 \mathrm{~nm}$ with a plate reader. Control values were set to $100 \%$ of cell viability. Cytotoxicity data was fitted to a sigmoidal curve and a three-parameter logistic 
model was used to calculate the $\mathrm{IC}_{50}$, which is the concentration of articles causing $50 \%$ inhibition in comparison to untreated controls. The mean $\mathrm{IC}_{50}$ is the concentration of agent that reduces cell growth by $50 \%$ under the experimental conditions and is the average from at least three independent measurements that were reproducible and statistically significant. These analyses were performed with GraphPad Prism.

ROS Production Assay in Microglia Cells: The ROS generation in the microglia cells were determined using DCFDA assay. Microglia cells were plated in the white wall coated 96-well plate with density of 20,000 cells per well and grown for $16 \mathrm{~h}$. The SQV, EFV, DRV, DTG, EVG and their nanoformulations were added to the cells at concentration of $1 \mu \mathrm{M}$ with respect to the ARTs for $24 \mathrm{~h}$. After $24 \mathrm{~h}$, the media was collected and used to determine IL-1 $\beta$, an inflammation maker using commercially available kit. The DCFDA solution was made in media at the concentration of $100 \mu \mathrm{M} .100 \mu \mathrm{L}$ of this solution was added to each well and cells were incubated for $30 \mathrm{~min}$. The cells were washed with 1X PBS for 3 times and fluorescence of DCF was recorded at 495/528 $\mathrm{nm}$ (ex/em) using a BioTek Plate Reader. The obtained values were normalized using BCA assay.

ELISA in Microglia Cells: Using the supernatant from the assay, ELISA was carried out according to the manufacturer's instructions. Briefly, a 96-well plate was coated with $100 \mu \mathrm{L}$ of capture antibody overnight at $4{ }^{\circ} \mathrm{C}$. The plate was washed with washing buffer, tapped on a paper towel, and blocked with blocking buffer for $1 \mathrm{~h}$ at room temperature. Samples and standards were added to their respective wells and incubated for $2 \mathrm{~h}$ at room temperature. The plate was washed with washing buffer and tapped on paper towel 5 times. $100 \mu \mathrm{L}$ of working detector solution was added to the well and incubated for $1 \mathrm{~h}$ at room temperature. After extensive washing, $100 \mu \mathrm{L}$ of substrate solution was added to each well and incubated for 30 
minutes at room temperature in the dark. Then, $50 \mu \mathrm{L}$ of stop solution was added to each well and absorbance was recorded at $450 \mathrm{~nm}$ using a plate reader. The obtained values were normalized using BCA assay.

Mitostress Assay: Different parameters of mitochondrial respiration such as basal respiration, maximal respiration, and ATP production were investigated using Seahorse XFe96 Analyzer. One day prior to the assay, XF sensor cartridges were hydrated using $200 \mu \mathrm{L}$ of XF calibrant buffer and kept at $37{ }^{\circ} \mathrm{C}$ incubator without $\mathrm{CO}_{2}$ overnight. Cells were plated at a density of 20,000 cells per well in $50 \mu \mathrm{L}$ DMEM media (with 10\% FBS) and the plate was kept $1 \mathrm{~h}$ at room temperature followed by incubation at $37^{\circ} \mathrm{C}$ with $5 \% \mathrm{CO}_{2}$ for $3 \mathrm{~h}$. Finally, $130 \mu \mathrm{L}$ of fresh media was added to have total $180 \mu \mathrm{L}$ per well and incubated for $16 \mathrm{~h}$. Cells were treated with cocaine and Meth from 0 to $500 \mu \mathrm{M}$ for $24 \mathrm{~h}$. Before conducting the Mitostress assay, Seahorse media (XF Assay Medium Modified DMEM) was reconstituted with glucose $(1.8 \mathrm{mg} / \mathrm{mL}$ ), sodium pyruvate $(1 \%)$ and L-glutamine (1\%) and adjusted for $\mathrm{pH} 7.4$ by using $0.1 \mathrm{~N} \mathrm{NaOH}$. The cells were washed thrice with freshly prepared seahorse medium and incubated at $37^{\circ} \mathrm{C}$ in non- $\mathrm{CO}_{2}$ incubator for $1 \mathrm{~h}$. Meanwhile, cartridge ports were added with various inhibitors. The stocks of oligomycin $(10 \mu \mathrm{M}), \mathrm{FCCP}(10 \mu \mathrm{M})$ and antimycin-A/rotenone mixture (10 $\mu \mathrm{M}$ each) were made in seahorse media. The port A was filled with $20 \mu \mathrm{L}$ of oligomycin, port B with $22 \mu \mathrm{L}$ of FCCP and port C with $25 \mu \mathrm{L}$ of antimycin $\mathrm{A} /$ rotenone to have a final concentration of $1 \mu \mathrm{M}$ in each well. The cartridge was calibrated for $\mathrm{pH}$ and $\mathrm{O}_{2}$. After calibration, the experiment plate was run where 3 measurements were recorded for basal OCR and after addition of each reagent. The media was aspirated and $20 \mu \mathrm{L}$ of RIPA buffer was added to each well and incubated for 10 mins at 37 ${ }^{\circ} \mathrm{C}$. Further $\mathrm{BCA}$ assay was performed to obtain protein normalized $\mathrm{OCR}$ values. 


\section{HIV-1 Propagation and Expansion in Peripheral Blood Mononuclear Cells (PBMCs):}

PBMCs were separated from blood samples by using the density gradient method previously reported. ${ }^{3-4}$ Isolated PBMCs were incubated at the density of $5 \times 10^{7}$ cells in $30 \mathrm{~mL}$ of RPMI for overnight. Next add $3 \mu \mathrm{g} / \mathrm{mL}$ of PHA was added to activate the cells. After $72 \mathrm{~h}$, cells were centrifuged, and the pellet was resuspended in $10 \mathrm{~mL}$ of RPMI containing $2 \mu \mathrm{g} / \mathrm{ml}$ polybrene and incubated for $30 \mathrm{~min}$. To this mixture HIV virus $20 \mathrm{ng}$ per $1^{*} 10^{7}$ cells was added and incubated for $2 \mathrm{~h}$ at $37^{\circ} \mathrm{C}$. Cells were centrifuged and washed with PBS 3 times to remove unbound virus and resuspended the pellet in T75 flask with IL-2 containing $30 \mathrm{~mL}$ of RPMI. Incubated the cells at $37^{\circ} \mathrm{C}, 5 \% \mathrm{CO}_{2}$. Every two days' supernatant was centrifuged, and half of the media was changed with IL-2 containing RPMI. Supernatant media collected on day 7, 10 and 14 was used to estimate the amount of p24 in the culture supernatants using an ELISA kit. Aliquots of this supernatant was used for virus infection experiments.

\section{Sequential Treatment Approach in Microglia Cells Infected with HIV-1 BaL Virus:}

Sequence treatments were performed to mimic HIV-infected human exposure to drugs of abuse, followed by treatment with ART-NP and NP-delivered antioxidants. Microglia cells were plated in a 6-well plate with a density of 50,000 cells per well. On day 1, cells were infected with 41 $\mathrm{ng} / \mathrm{mL}$ of HIV clade-B virus and incubated for $24 \mathrm{~h}$. After, the media was aspirated, and meth was added at the concentration of $500 \mu \mathrm{M}$ and incubated for $24 \mathrm{~h}$. Media was aspirated, and EFV-NP and EVG-NP were added at concentrations of $1 \mu \mathrm{M}$ and $0.5 \mu \mathrm{M}$ respectively with respect to the loaded cargos for $24 \mathrm{~h}$. Finally, media was aspirated and $\mathrm{T}-(\mathrm{Asp})_{4} / \mathrm{CoQ}_{10}-\mathrm{NPs}$ were added at the concertation of 10 with respect to [Oc-G2-(Asp) 4 and $\mathrm{CoQ}_{10}$ for additional 24 h. Each media sample was used for analysis of inflammation markers present after each stage of exposure or treatment. 
Experimental approach in Microglia cells co-culture with astrocytes: Sequence treatments and co-culture of microglia cells with astrocytes were performed to mimic HIV-infected human exposure to drugs of abuse in the brain microenvironment. Microglia cells were plated in a 6well plate with a density of 50,000 cells per well. On day 1 , cells were infected with $10 \mu \mathrm{g} / 10,000$ cells of mito-GFP for $48 \mathrm{~h}$ to maximize the GFP staining of the mitochondria. On day 3 , cells were infected with $200 \mathrm{ng} / \mathrm{mL}$ of TAT peptide and incubated for $48 \mathrm{~h}$. After that, on day 5 the media was aspirated, and $500 \mu \mathrm{M}$ of meth was added and cells were incubated for $24 \mathrm{~h}$. Media was then aspirated and the combination of T-EFV-NP + T-EVG-NP + T-DRV-NP, $0.5 \mu \mathrm{M}$ each, were added, and cells were incubated for $24 \mathrm{~h}$. On day 5 of this experiment, in a separate 6-well plate, astrocytes were plated with density of 50,000 cells per well and treated after $24 \mathrm{~h}$ with T(Asp) $4-\mathrm{NP}+\mathrm{T}-\mathrm{CoQ}_{10}-\mathrm{NP}$ at a concentration of $10 \mu \mathrm{M}$ each with respect to articles loaded inside. Finally, the media from the microglia culture was aspirated and the astrocytes were added and co-cultured with microglia cells for $24 \mathrm{~h}$. On day 8 , the microglia cells were sorted using cell sorter and tested for ROS levels using mito-SOX reagent. Each media sample was used for analysis of inflammation markers present after each stage of exposure or treatment. The experiment mentioned above was performed in live cell imaging dishes to study the Mito-SOX staining.

ATP production assay: ATP production assay was done using kit Cell Titer-Glo, Promega. 2000 cells were seeded in white wall 96 well plate and incubated overnight at $37^{\circ} \mathrm{C}$ for $1 \mathrm{~h}$ allow the cells to settle down. The cells plate was centrifuged at $2000 \times \mathrm{g}$ at $4{ }^{\circ} \mathrm{C}$ for $5 \mathrm{~min}$. Later on the media was removed and $100 \mu \mathrm{L}$ of Cell Titer-Glo solution was added and incubated for 10 minutes at room temperature. Luminescence signal was recorded in plate reader. The obtained values were normalized using BCA assay. 
ROS production assay by Immunofluorescence: ROS production levels at mitochondria analyzed using Mito-SOX staining. On the final day of the experiment, cells were washed with PBS and mito-SOX solution $(0.1 \mathrm{mg} / \mathrm{mL})$ in DMEM was added and incubated for 30 min at room temperature in the dark. The media was removed, and the cells were then washed gently with PBS (3X). Finally, $1 \mathrm{~mL}$ of PBS was added to the cells and the cells were imaged using confocal microscopy. Confocal images were recorded using an Olympus FluoView FV3000 confocal microscope using $405 / 460 \mathrm{~nm}$ for DAPI and $510 / 580 \mathrm{~nm}$ for mitoSOX. Sampling speed was kept as $8.0 \mathrm{us} /$ pixel (0.55 min per image). Images were analyzed using the software ImageJ.

Biodistribution of ARV-loaded NPs: The distribution and toxicity of the free ARVs and ARVloaded nanoparticles was carried out in female BALB/c mice after intravenous administration. Saline-treated mice were used as a control. The animals were divided into seven groups: saline $(n=4), \operatorname{EFV}(n=3), \operatorname{DRV}(n=3), \operatorname{EVG}(n=3), T-E F V-N P(n=4), T-D R V-N P(n=4)$, and T-EVG-NP $(n=4)$, here $n$ is number of animals used in the group. The animals received saline treatment, ARV treatment or ARV-NP treatment via intravenous injection. The dose of nanoparticle was kept as $40 \mathrm{mg} / \mathrm{kg}$ with respect to ARV weight. After $24 \mathrm{~h}$ of injection, under anesthesia around $200 \mu \mathrm{L}$ of blood was collected via cardiac puncture and perfusion was carried out with 1X PBS for $10 \mathrm{~min}$ with a flow rate of $7 \mathrm{~mL} / \mathrm{min}$. After perfusion, the animals were sacrificed, and organs were harvested. The collected blood was centrifuged to collect blood plasma. The collected organs were weighed and homogenized using a dounce homogenizer and collected in $5 \mathrm{~mL}$ of methanol. To spike the ARV peak, $20 \mu \mathrm{g} / \mathrm{mL}$ of the respective ARV was added to the crushed tissues and to the blood plasma. This mixture was sonicated for $20 \mathrm{~min}$ followed by centrifugation at $14000 \mathrm{rpm}$ for $10 \mathrm{~min}$. From the precipitated debris, supernatant was gently collected. Meanwhile, Strata-X columns were activated by passing $1 \mathrm{~mL}$ of methanol and $1 \mathrm{~mL}$ of water 
through the filter in sequence. The collected supernatant was passed through the activated column to get rid of remaining debris and impurities. The column was washed with $1 \mathrm{~mL}$ of $5 \%$ methanol to remove the impurities. The ART from the column was collected in $1.5 \mathrm{~mL}$ of methanol and quantified using HPLC (wavelength = efavirenz (27.3 min, $268 \mathrm{~nm})$, darunavir (24.0 $\mathrm{min}, 268 \mathrm{~nm}$ ), and elvitegravir (27.9 $\mathrm{min}, 268 \mathrm{~nm})$.

Aspartate Aminotransferase (AST) Activity Assay: The collected blood plasma was used to determine AST activity. All samples and standards were studied in duplicates. AST levels in blood are commonly used as a marker for liver function. The collected serum samples were directly used to determine the AST levels. From each sample, $50 \mu \mathrm{L}$ of serum was added to a 96-well plate. Along with this, $50 \mu \mathrm{L}$ glutamate standards were also added, with concentrations of $0,2,4,6,8$, and $10 \mathrm{nmol} /$ well prepared in AST assay buffer. To each well, $100 \mu \mathrm{L}$ of master reaction mix (80 $\mu \mathrm{L}$ of AST Assay Buffer, $2 \mu \mathrm{L}$ of AST Enzyme Mix, $8 \mu \mathrm{L}$ of AST Developer and $10 \mu \mathrm{L}$ of AST Substrate) was added and incubated for $5 \mathrm{~min}$ at $37^{\circ} \mathrm{C}$ in the dark. Meanwhile, the plate reader was set for $37^{\circ} \mathrm{C}$ and kept ready to read the kinetics, with 5 min intervals, for 20 min. Absorbance at initial time, $T_{\text {Initial, }}$ was $\left(A_{450}\right)_{\text {Initial, }}$, and at the end the final time point, $T_{\text {final, }}$ was $\left(A_{450}\right)_{\text {final. }}$. The final absorbance should not exceed the highest standard $(10 \mathrm{nmol} / \mathrm{well})$ absorbance value. It is essential that $\left(A_{450}\right)$ final is in the linear range of the standard curve. The absorbance was measured at $450 \mathrm{~nm}$ at the initial time.

Calculated the change in absorbance from $T_{\text {initial }}$ to $T_{\text {final }}$ for the samples.

$$
\Delta \mathrm{A}_{450}=\left(\mathrm{A}_{450}\right)_{\text {final }}-\left(\mathrm{A}_{450}\right)_{\text {initial }}
$$

The amount of generated glutamate using standard curve determined for above obtained $\Delta \mathrm{A}_{450}(\mathrm{~B})$. 
The AST activity of a sample was determined by the following equation:

AST Activity $($ milliunit $/ \mathrm{mL})=\mathrm{B} /$ Reaction Time * $\mathrm{V}$

$B=$ Amount (nmole) of glutamate generated between $T_{\text {initial }}$ and $T_{\text {final. }}$ Reaction Time ( $\mathrm{min}$ )

$=\mathrm{T}_{\text {final }}-\mathrm{T}_{\text {initial }}$

$\mathrm{V}=$ sample volume $(\mathrm{mL})$ added to well

Alanine Transaminase (ALT) Colorimetric Activity Assay: The collected plasma was used to determine ALT activity. Cayman's ALT Assay Kit was used to detect ALT activity in plasma. Measurement of the ALT activity is carried out by monitoring the rate of NADH oxidation in a coupled reaction system employing lactate dehydrogenase (LDH). The oxidation of NADH to $\mathrm{NAD}+$ is accompanied by a decrease in absorbance at $340 \mathrm{~nm}$. Under circumstances in which the ALT activity is rate limiting, the rate decrease is directly proportional to the ALT activity in the sample. This experiment was carried out in 96-well plate provided by Cayman. First, $150 \mu \mathrm{L}$ of substrate, $20 \mu \mathrm{L}$ of Cofactor, and $20 \mu \mathrm{L}$ of sample were added to each well and incubated for at $37^{\circ} \mathrm{C}$ for $15 \mathrm{~min}$. The reaction was initiated by the addition of $20 \mu \mathrm{L}$ of ALT initiator to all of the wells with minimal time difference between addition to the wells. Absorbance was recorded immediately at $340 \mathrm{~nm}$ once every minute for a period of five minutes.

The change in absorbance ( $\triangle \mathrm{A} 340)$ per minute was determined by selecting two linear points on the linear portion of the curve and calculated the change in absorbance using the following equation.

$$
\Delta \mathrm{A} / \min =\mathrm{A}_{340}(\text { Time } 2)-\mathrm{A}_{340}(\text { Time } 1) / \text { Time } 2(\min )-\text { Time } 1(\min )
$$


ALT activity was determined using following formula $=\left(\Delta \mathrm{A}_{340} / \mathrm{min} \times 0.21 \mathrm{~mL}\right) \times 4.11 \mathrm{mM}^{-}$ ${ }^{1} \times 0.02 \mathrm{~mL}$. The reaction rate at $340 \mathrm{~nm}$ can be determined using the NADH extinction coefficient of $4.11 \mathrm{mM}^{-1}$.

Creation of Mice Model of Intravenous Drug Use in HIV-Positive animals: The experiment was carried out in male C57BL/6 mice (13 weeks, Jackson laboratory) with an average weight of $25 \mathrm{~g}$. C57BL/6 male mice were divided into 12 groups and were assigned to the following treatment groups: control virus + Meth + saline (12 animals); control virus + saline (12 animals); control virus + Meth + T-CoQ ${ }_{10}-\mathrm{NP} / \mathrm{T}-(\mathrm{Asp})_{4}-\mathrm{NP}$ (13 animals); EcoHIV + Meth + saline (11 animals); EcoHIV + Meth + T-CoQ ${ }_{10}-\mathrm{NP} / \mathrm{T}-(\mathrm{Asp})_{4}-\mathrm{NP}$ (10 animals); EcoHIV + Meth + T-ARTNPs (12 animals); EcoHIV + Meth + T-ART-NP + T-CoQ ${ }_{10}-\mathrm{NP} / \mathrm{T}-(\mathrm{Asp})_{4}-\mathrm{NP}$ (16 animals); control Virus + Meth + T-CoQ $10 /($ Asp) 4 -NPs (11 animals); control Virus + T-ART-NPs (13 animals); control Virus + T-ART-NPs + T-CoQ ${ }_{10} /(\text { Asp })_{4}-\mathrm{NPs}$ (12 animals), saline (3 animals), and EcoHIV + saline ( 3 animals). The mice were infused with a chimeric HIV-NDK (abbreviated as EcoHIV, $1 \mu \mathrm{g}$ of p24 in $100 \mu \mathrm{l}$ ) via lateral tail vein injection. ${ }^{5}$ A retroviral vector pBMN-I-GFP (Addgene, Plasmid \#1736) was employed to generate control murine retrovirus (ConV) in Phoenix-Eco packaging cells from ATCC (CRL-3214). One week later those mice were injected intraperitoneally with meth three times a day with a $3 \mathrm{~h}$ interval. We applied an escalating dose regimen starting with $1.0 \mathrm{mg} / \mathrm{kg}$ with a constant increase of $0.2 \mathrm{mg} / \mathrm{kg}$ at each injection for 5 days. Control mice were injected with saline as a vehicle. After the last methamphetamine injection, nanoparticles were injected. T-ART-NPs were always given as a combination of the three types of drug loaded nanoparticles, T-EFV-NP, T-DRV-NP, and T-EVG-NP, and were each given at dose of $5 \mathrm{mg} / \mathrm{kg}$ with respect to each drug. T-CoQ ${ }_{10}-\mathrm{NP} / \mathrm{T}-(\mathrm{Asp})_{4}-\mathrm{NP}$ were injected at a dose of $20 \mathrm{mg} / \mathrm{kg}$ with respect to $\mathrm{CoQ}_{10}$ or $(\mathrm{Asp})_{4}$. The T-ART-NP followed by T-CoQ $10-\mathrm{NP} / \mathrm{T}$ - 
(Asp) ${ }_{4}$-NP injections were conducted twice a week, for a total of 4 injections per week. Injections of T-ART-NP on day 1 would be followed by T-CoQ ${ }_{10}-\mathrm{NP} / \mathrm{T}-(\mathrm{Asp})_{4}-\mathrm{NP}$ on day 2 , and this cycle would repeat on day 4 and day 5 . This entire T-ART-NP and T-CoQ ${ }_{10}-\mathrm{NP} / \mathrm{T}-(\mathrm{Asp})_{4}$-NP treatment regimen was conducted for a total of 2 weeks. After the second week, animals were sacrificed, and blood and organs were collected. Blood was collected via cardiac puncture, then the mice were perfused with PBS at $7.5 \mathrm{~mL} / \mathrm{min}$ to remove trace amounts of blood from organs. The collected blood samples were centrifuged to collect blood plasma. Organs from half of the mice of each group were snap-frozen for future RT-PCR analysis, while the other half were fixed in 4\% PFA for immunofluorescence and histopathology. Organs stored in PFA were submitted for sectioning for H\&E analysis.

ELISA for Analyses of HIV Infection: An ELISA kit from Zeptomatrix was also used to measure levels of the p24 antigen in the blood plasma from mice. First, plates washed with washing buffer and tapped on a paper towel, after which $200 \mu \mathrm{L}$ of standards or samples were prepared and added to the wells and the plate was incubated for $2 \mathrm{~h}$ at $37^{\circ} \mathrm{C}$. The plate was washed with washing buffer and tapped on paper towel, and $100 \mu \mathrm{L}$ of detector antibody was added to each well, and the plate was incubated for $1 \mathrm{~h}$ at $37^{\circ} \mathrm{C}$. The plate was then washed again, $100 \mu \mathrm{L}$ of substrate was added to each well, and the plate was incubated for $30 \mathrm{~min}$ at room temperature. Then $100 \mu \mathrm{L}$ of stop solution was added and absorbance was recorded at $450 \mathrm{~nm}$ using a plate reader.

RT-PCR Study: To measure the p24 antigen RNA levels in the brain lysates of treated mice, qPCR was utilized. RNA was extracted using kit from Qiagen. Briefly, cells were lysed with buffer RLT. One volume of $70 \%$ ethanol was added to the cell lysate and mixed well. Lysates were transferred to RNeasy mini spin column and centrifuged for $1 \mathrm{~min}$ at $8000 \mathrm{xg}$. Flow-through was 
discarded. $700 \mu \mathrm{L}$ of buffer RW1 was added to the mini spin column and centrifuged for 1 for minute at $8000 x g$. Flow-through was discarded. A portion of $500 \mu \mathrm{L}$ of buffer RPE was added to the mini spin column and centrifuged for 1 minute at $8000 \mathrm{xg}$. RNA was recovered from mini spin column using RNase-free water. Purity and concentration of RNA was checked using Nanodrop. Reverse transcription from each sample was carried out using $1 \mu \mathrm{g}$ of RNA from each sample in a $20 \mu \mathrm{L}$ reaction volume using iScript Reverse Transcription Supermix for RT-qPCR kit from Bio-Rad. Real time PCR reaction was carried out using SsoAdvanced Universal SYBR ${ }^{\circledR}$ Green Supermix in $20 \mu \mathrm{L}$ reaction. The house keeping gene, $\beta$-actin was used as an internal control. Data were analyzed according to the comparative $\mathrm{Ct}$ value and expressed as fold change 2- $\triangle \triangle C T$. HIV was assessed using the following primers and probe: NDKgag_F 5'GACATAAGACAGGGACCAAAGG-3'; NDKgag_R 5'-CTGGGTTTGCATTTTGGACC-3'. The primer sequence for $\beta$-actin gene was: Forward 5'GCATCCTCACCCTGAAGTAC 3 ' and reverse 5'GATAGCACAGCCTGGATAGC3'. GAPDH (4326317E), C3 (Mm00437859_g1) and OLFM1 (Mm00444666_m1) was purchased from Life Technologies. The primer sequence for GCLC gene was: Forward 5'ACACCTGGATGATGCCAACGAG3' and reverse 5'CCTCCATTGGTCGGAACTCTAC3'. The primer sequence for GCLM gene was: Forward 5' TCCTGCTGTGTGATGCCACCAG3' and reverse 5'GCTTCCTGGAAACTTGCCTCAG3'. The primer sequence for GPX7 gene was: Forward 5'CGACTTCAAGGCGGTCAACATC3' and reverse 5'AAGGCTCGGTAGTTCTGGTCTG3'.

Immunofluorescence of Harvested Tissue Samples: Organs harvested from the treated mice were stained with antibodies for GFAP, MAP2, TMEM119, ICAM-1, catalase, and HIV-1 p24. Tissue sections were heated at $60^{\circ} \mathrm{C}$ for $30 \mathrm{~min}$ followed by rehydration in an ethanol gradient. Antigen retrieval was carried out in a decloaking chamber. The sections were then washed with 
PBS (1X) 3 times and then permeabilized using $0.1 \%$ Triton-X 100 for 10 min at room temperature. The tissues were washed with 1X PBS 3 times and blocked with 1\% goat serum in 1X PBS for $1 \mathrm{~h}$ at room temperature. Sections were treated with the respective primary antibody in $1 \%$ goat serum containing $1 \times$ PBS for $16 \mathrm{~h}$ at $4{ }^{\circ} \mathrm{C}$ in humidified chamber. After washing the sections three more times with $1 \%$ goat serum containing $1 \times$ PBS, the respective secondary antibody (Alexa 488 conjugated antibody) solution in 1\% goat serum containing 1x PBS was added and incubated for $1 \mathrm{~h}$ at room temperature. Finally, DAPI stain was applied to the tissue for 5 minutes followed by 6 washes with PBS. Sections were finally washed three more times with $1 \%$ goat serum containing $1 \times$ PBS. The tissues were then covered with coverslips using mounting solution ( $\mathrm{n}$-propyl gallate, Tris and glycerol in nanopure water, $\mathrm{pH}=8.0$ ). Confocal images were recorded using an Olympus FluoView FV3000 confocal microscope using 405/460 $\mathrm{nm}$ for DAPI and 488/510 $\mathrm{nm}$ for Alexa488. Sampling speed was kept as $8.0 \mathrm{us} / \mathrm{pixel}$ (0.56 min per image).

Isolation of glial cells and DCFDA assay: To isolate the glial cells and neurons from brain samples, freshly harvested brains divided into two halves, out of which one half was used for isolation of glial cells and other half for isolation of neurons. The brain samples were gently crushed using a dounce homogenizer and the suspension was collected in glial dissection media and filtered through a $100 \mu \mathrm{m}$ cell strainer by using a sterile 30 glass tissue grinder pestle. $8 \mathrm{~mL}$ of glial culture medium was added drop wise to the surface of the cell strainer, and the cell suspension was collected in a $50 \mathrm{~mL}$ falcon tube. This cell suspension was passed through a 70 $\mu \mathrm{m}$ cell strainer, and the supernatant was collected in a new $50 \mathrm{~mL}$ falcon tube. The cell suspension was centrifuged at $1,000 \times \mathrm{g}$ for $5 \mathrm{~min}$ and then the supernatant was aspirated. The obtained pellet was resuspended in $1 \mathrm{~mL}$ of glial culture medium and cells were counted, and 
seeded for staining and ROS activity detection on coverslips in 12 well plate and white walled, clear bottom 96-well plate respectively incubated at $37{ }^{\circ} \mathrm{C}$ with $5 \% \mathrm{CO}_{2}$ and grown for $48 \mathrm{~h}$.

The remaining half of the brain was chopped into small dishes in a petri dish. These pieces were collected in neuronal dissection buffer and transferred to a $15 \mathrm{~mL}$ centrifuge tube. They were allowed to settle down in the buffer for $2 \mathrm{~min}$, and the buffer was aspirated carefully. $1 \mathrm{~mL}$ trypsin was added to the pieces, and they were incubated at $37^{\circ} \mathrm{C}$ in a water bath for 25 $\min$. While incubating, the tube was agitated every $5 \mathrm{~min}$. trypsin was then inactivated using prewarmed FBS solution, and the tissue pieces were allowed to settle down at room temperature. Once the pieces settled, the supernatant was carefully aspirated. $1.5 \mathrm{~mL}$ of pre-warmed DNAse solution ( $1 \mathrm{mg} / \mathrm{mL}$ in neurobasal media) was added and incubated for $20 \mathrm{~min}$ at $37^{\circ} \mathrm{C}$, which agitation every 5 minutes. The cells were dissociated by micropipette 20-30 times. The cells were allowed to settle at room temperature for $10 \mathrm{~min}$, and the supernatant was carefully transferred to a new $15 \mathrm{~mL}$ centrifuge tube and centrifuged at 15,000 RPM for $5 \mathrm{~min}$ at $4{ }^{\circ} \mathrm{C}$. The pellet was collected in neurobasal media and counted and plated in poly-D-Lysine coated coverslips in 12 well plate and white walled clear bottom 96-well plate for immunofluorescence and ROS activity assay respectively.

ROS Activity Assay: Glial and neuronal cells plated as state above were treated with 2',7'dichlorofluorescein diacetate (DCFH-DA) probe with concentration of $50 \mu \mathrm{M}$ and incubated for $30 \mathrm{~min}$. The 96 well plate was centrifuged at $5000 \mathrm{rpm}$ for $5 \mathrm{~min}$ at $4{ }^{\circ} \mathrm{C}$, the supernatant was aspirated, and cells were washed with PBS (1X) in dark condition. This centrifuge and washing step were repeated two times. After the final wash, $100 \mu \mathrm{L}$ of PBS was added to the cells and the fluorescence was determined at $485 \mathrm{~nm}$ excitation and $520 \mathrm{~nm}$ emission, using a microplate reader. 
Immunostaining of the Isolated cells: After cell isolation, cells were grown in selective media for 10 days on coverslips in a 12 well plate. The cells were washed with PBS (1X) 3 times and fixed with $4 \%$ paraformaldehyde for $15 \mathrm{~min}$ at $37^{\circ} \mathrm{C}$. After performing 3 washings, the cells were permeabilized using $0.1 \%$ Triton-X100 for $10 \mathrm{~min}$ at $37^{\circ} \mathrm{C}$. The cells were washed with PBS (1X) 3 times and blocked with $1 \%$ goat serum in $1 \mathrm{X}$ PBS for $12 \mathrm{~h}$. Cells were then treated with the respective primary antibody (GFAP and NeuN antibodies) in 1\% goat serum containing $1 \mathrm{X}$ PBS for $12 \mathrm{~h}$ at $4{ }^{\circ} \mathrm{C}$ in a humidified chamber. After washing the cells three times with $1 \%$ goat serum containing $1 \mathrm{X}$ PBS, the secondary antibody solutions in $1 \%$ goat serum containing $1 \mathrm{X}$ PBS were added and incubated for $1 \mathrm{~h}$ at room temperature in a humidified chamber. The cells were washed with 1 X PBS for 3 times and DAPI (1 mg/mL in 1 X PBS) was added to the cells and incubated for $5 \mathrm{~min}$ at room temperature. Cells were finally washed three more times with 1X PBS. The membrane was gently removed and kept on glass slides and covered with coverslips using mounting solution (n-propyl gallate, Tris and glycerol in nanopure water, $\mathrm{pH}=$ 8.0). Confocal images were recorded using an Olympus FluoView FV3000 confocal microscope using 405/460 nm for DAPI and 488/510 nm for Alexa488. 

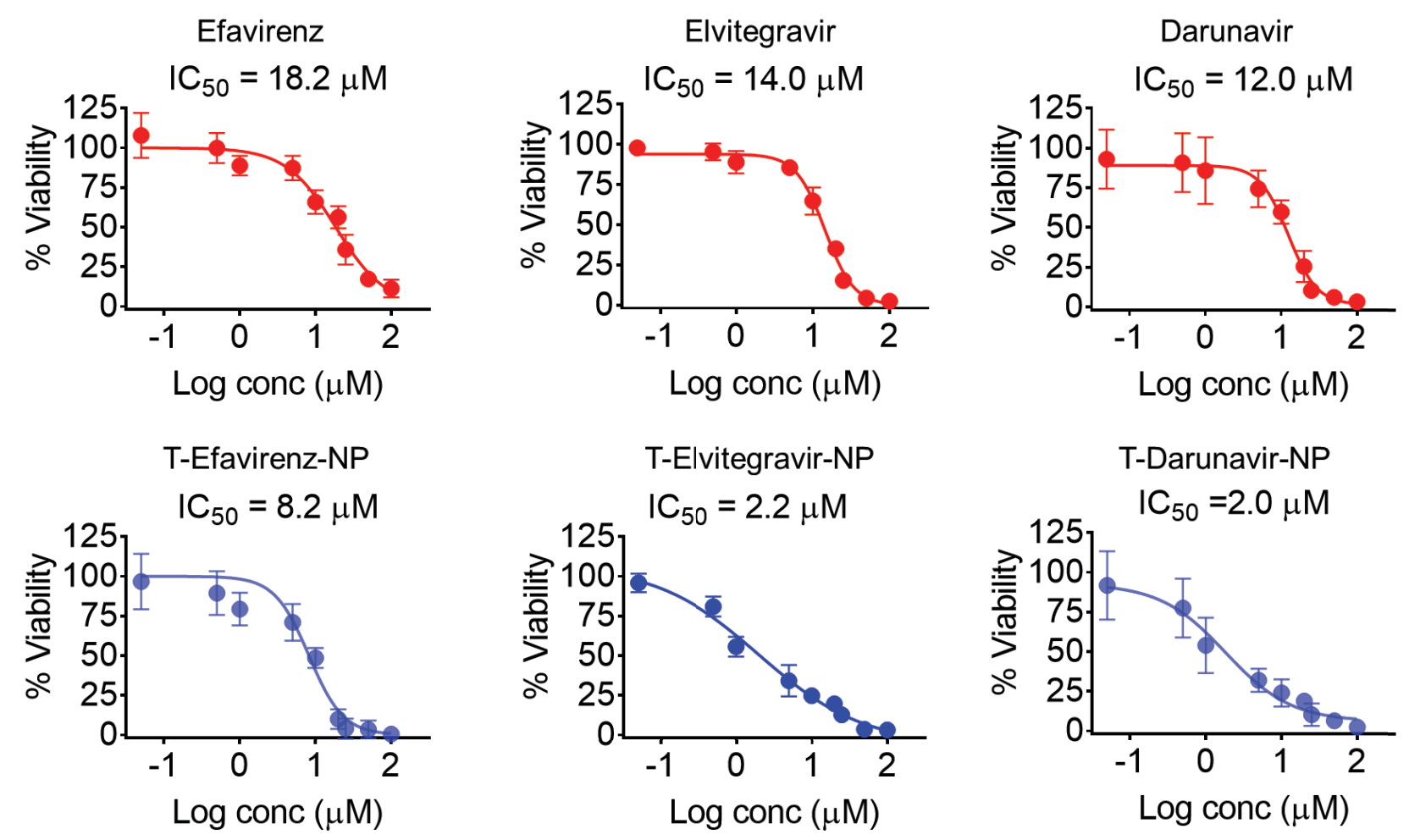

Figure S1. Cell viability of EFV, EVG, DRV, and their nanoformulations, tested at concentrations from $50 \mathrm{nM}$ to $100 \mu \mathrm{M}$ for $72 \mathrm{~h}$ in microglia. 

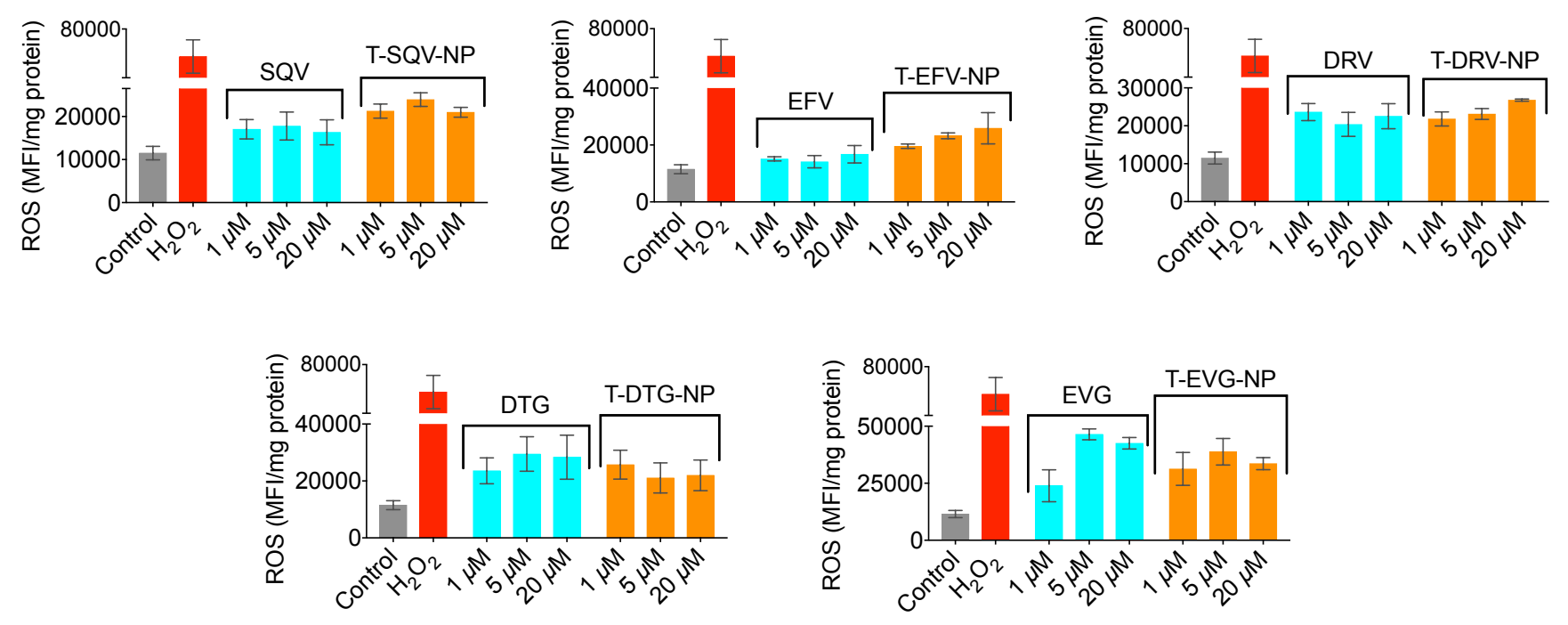

Figure S2. Elevated intracellular ROS levels in microglia cells treated with different concentrations of SQV, EFV, DRV, DTG, EVG or the nano-formulations T-SQV-NP, T-EFV-NP, T-DRV-NP, T-DTG-NP, TEVG-NP for $24 \mathrm{~h}$. 
(A)

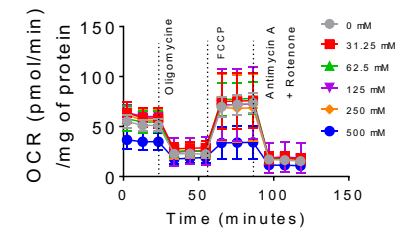

(B)

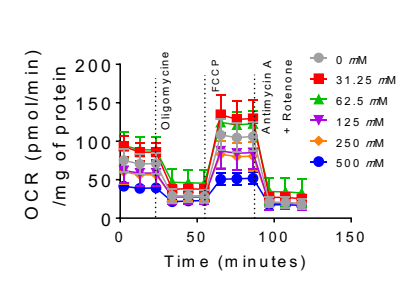

Basal Respiration

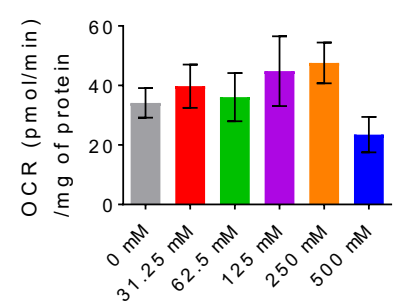

Basal Respiration

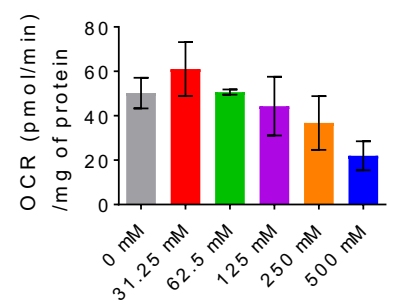

Maximal Respiration

A TP Production
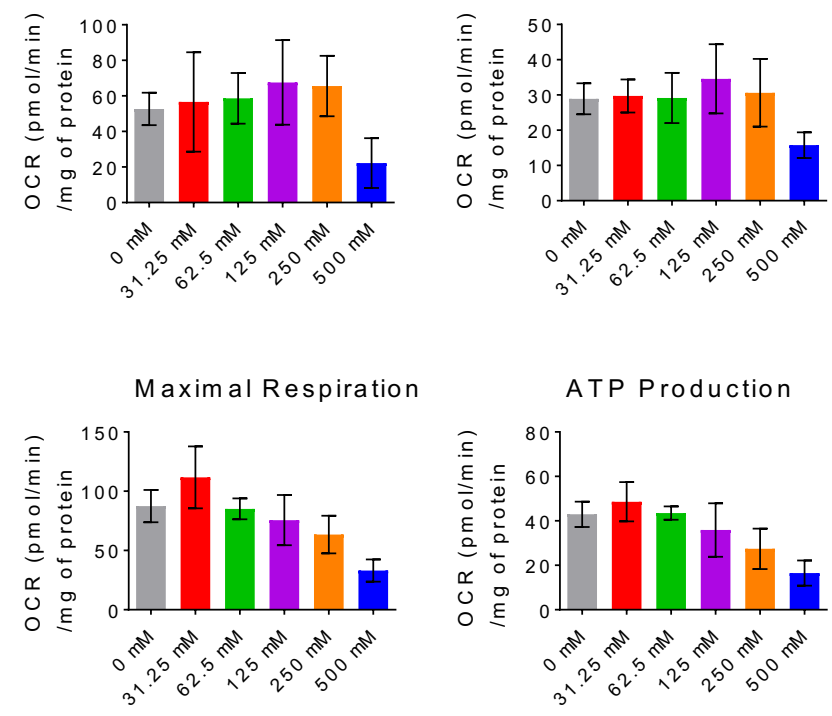

A TP Production

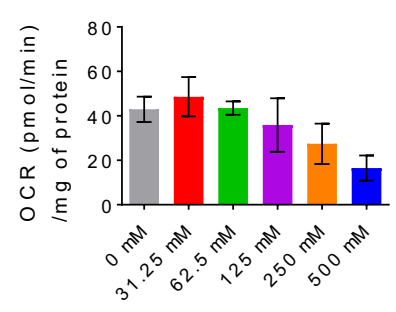

Figure S3. Effects of $(A)$ cocaine and $(B)$ meth on mitochondrial basal respiration, maximal respiration, and ATP production as determined by Seahorse Mitostress analyses in astrocytes. The article concentration was varied from 0 to $500 \mu \mathrm{M}$ and cells were treated for $24 \mathrm{~h}$. 

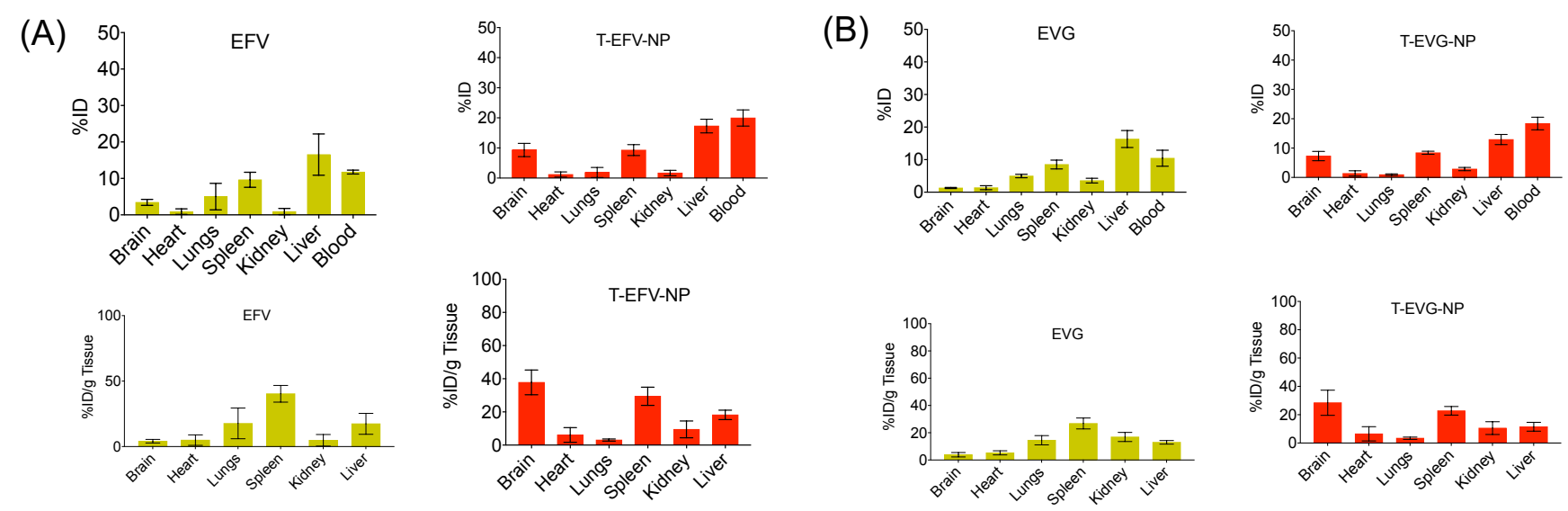

(C)
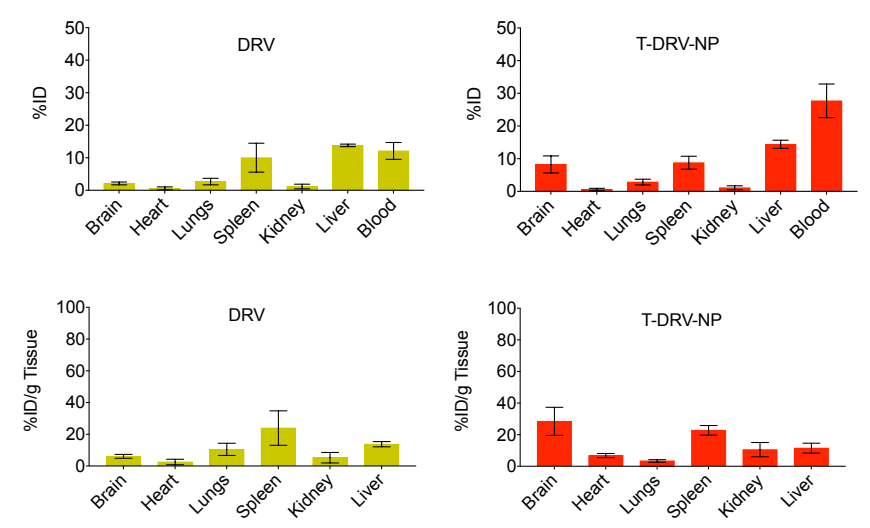

Figure S4. Distribution of intravenously injected T-ARV-NPs in the brain and blood of female Balb/c mice for (A) EFV and T-EFV-NP, (B) EVG and T-EVG-NP and (C) DRV and T-DRV-NP. 
(A)
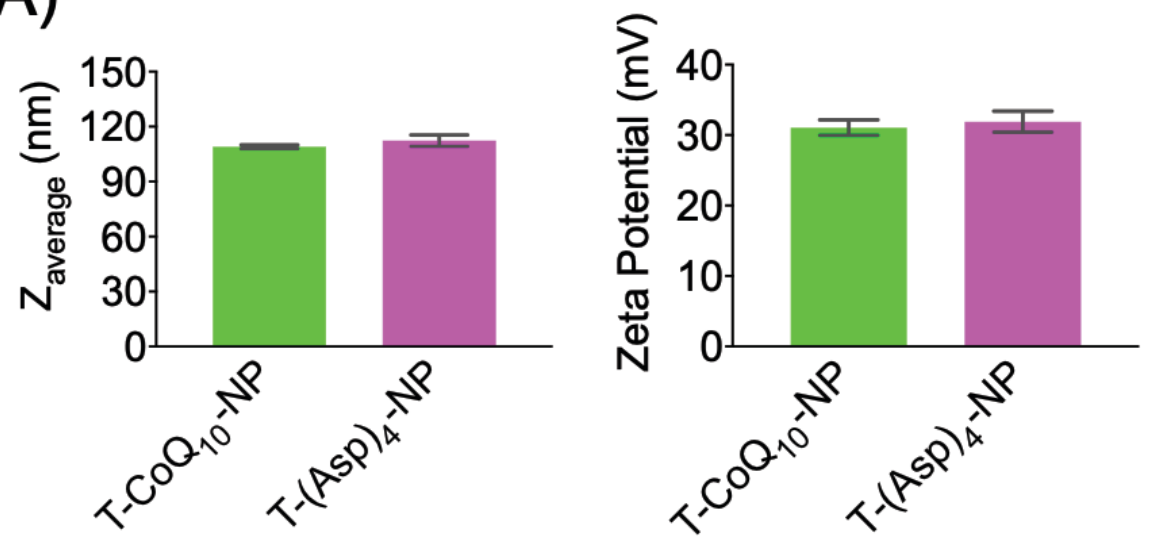

(B)
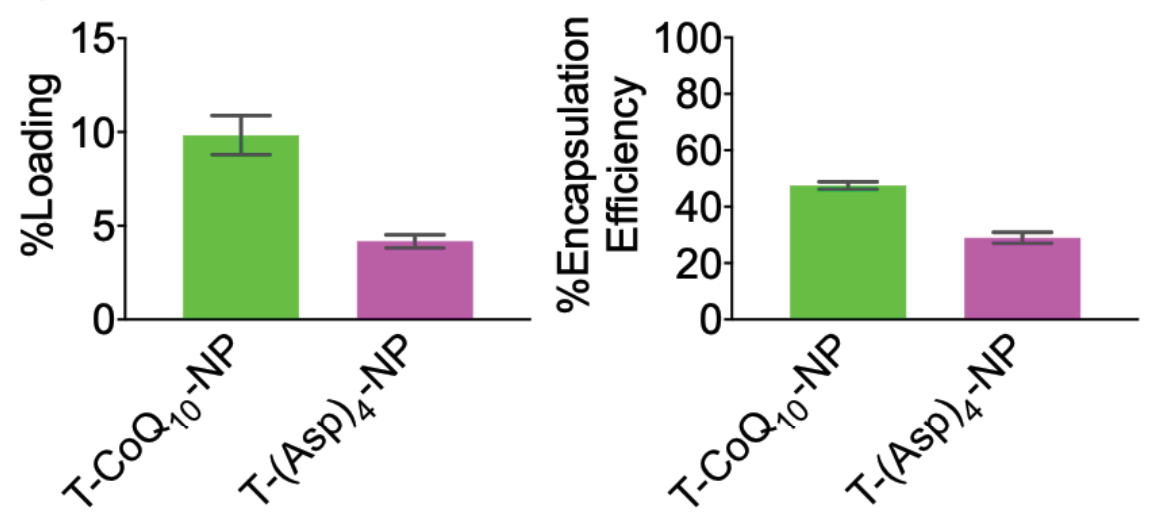

Figure S5. Zaverage hydrodynamic diameter, surface charge in terms of zeta potential, \%loading and \%encapsulation efficiency of T-CoQ ${ }_{10}-\mathrm{NP}$ and T-(Asp) 4 -NP. 

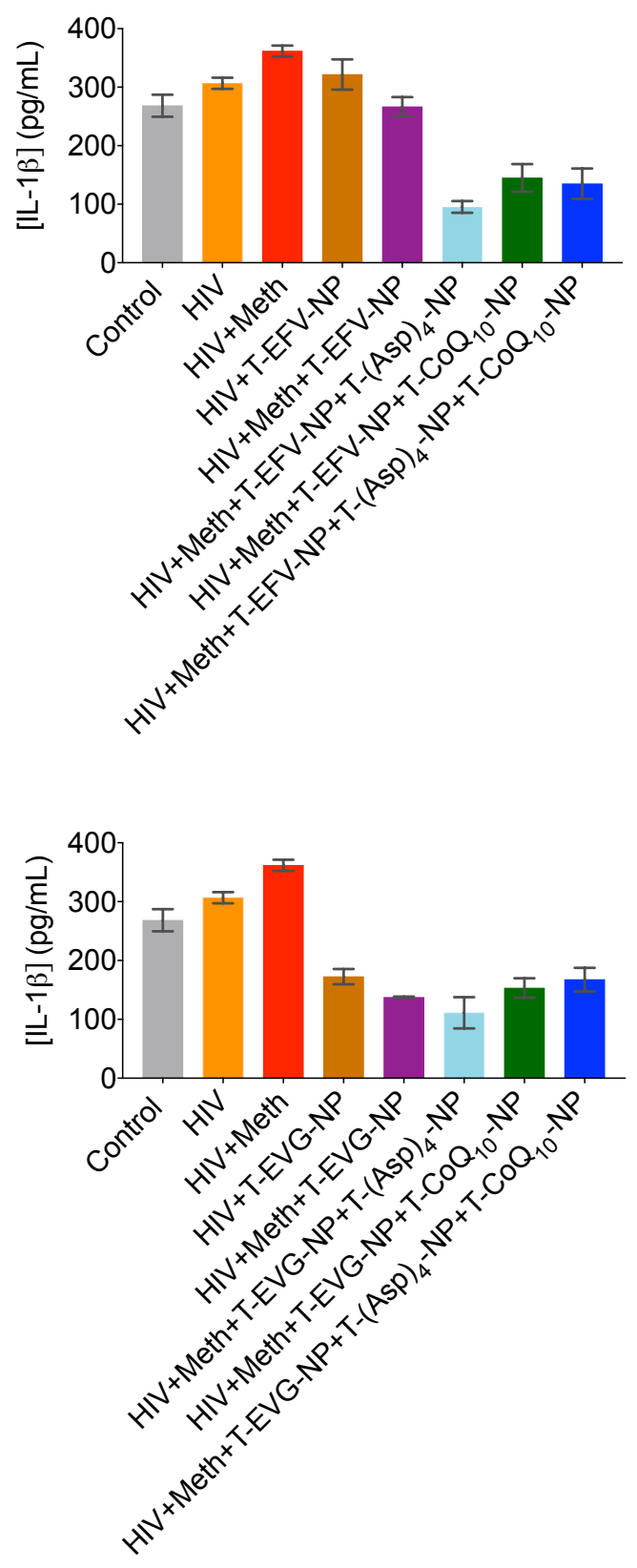

Figure S6. HIV-infected human microglia cells were treated with drugs of abuse meth to elevate the responses further. The cells were then treated with T-EVG-NP or T-EFV-NP and then treated with T(Asp) $)_{4} \mathrm{NP}$ and $\mathrm{T}-\mathrm{CoQ}_{10}-\mathrm{NP}$. Inflammatory responses in cell supernatants by analyzing IL-1 $\beta$. 
Unstained Cells
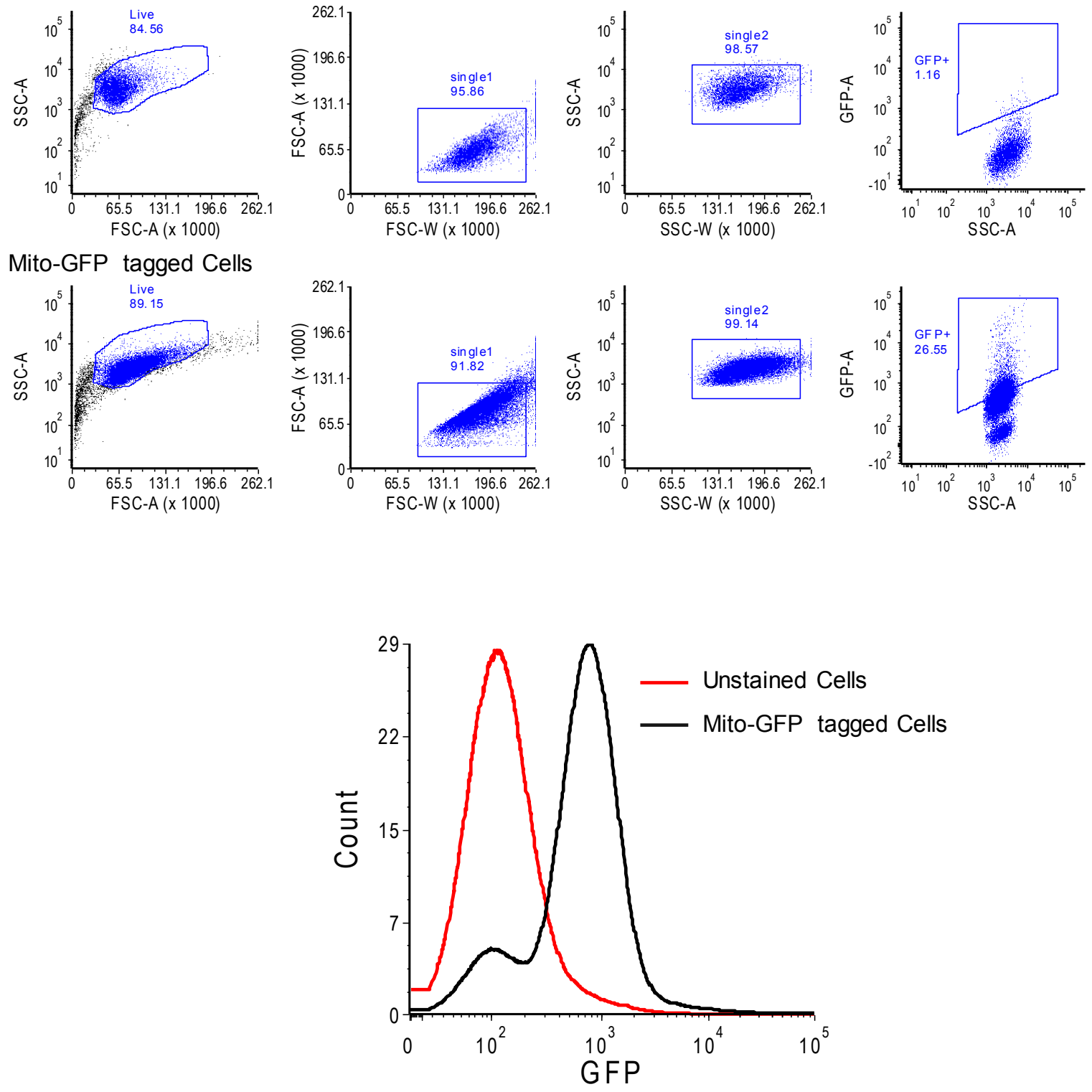

Figure S7. Representative flow cytometry data and gating of Mito-GFP tagged microglia cells from non-stained cells. 


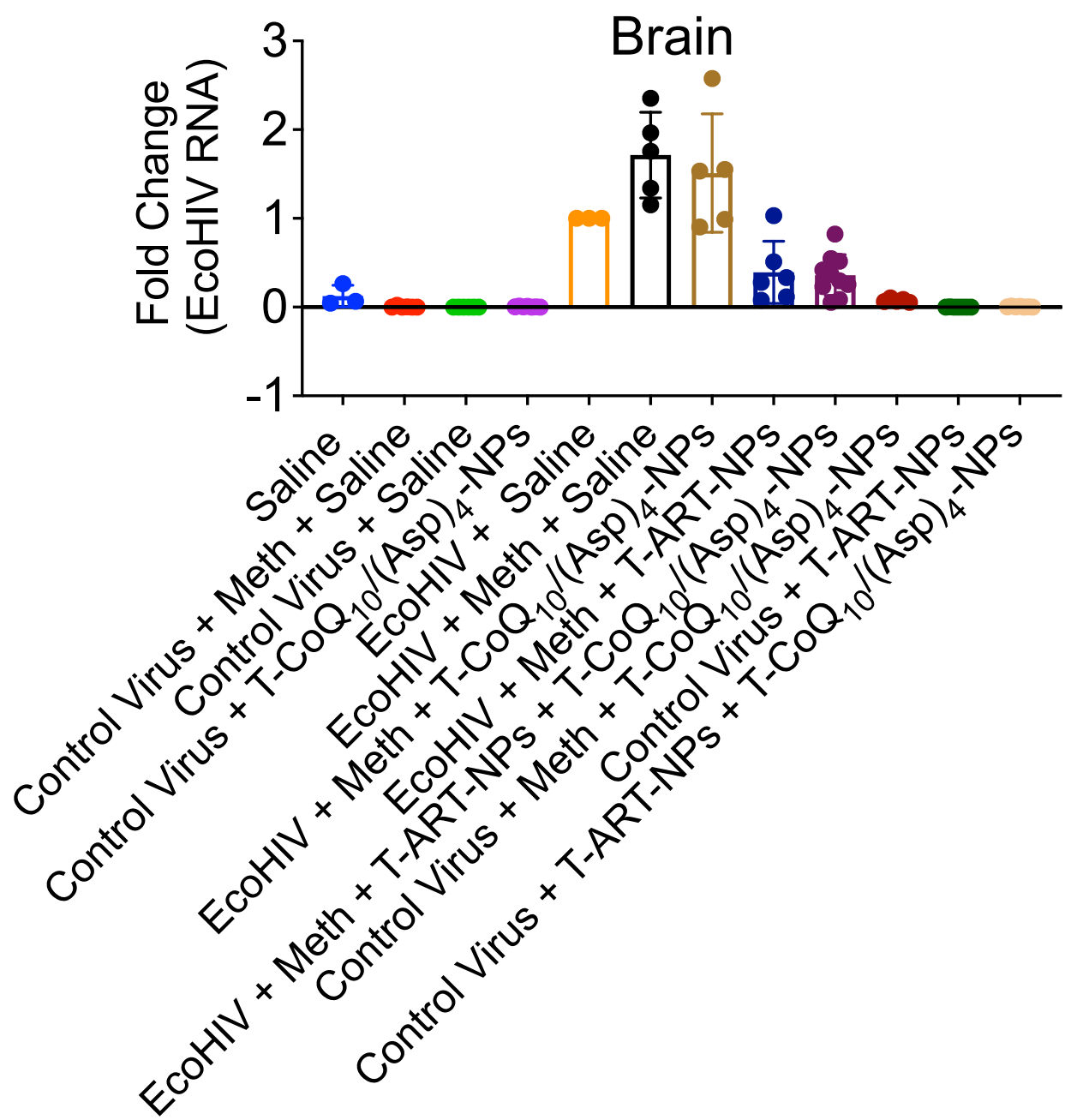

Figure S8. Efficacy studies in EcoHIV infected Meth treated animal model. Levels of EcoHIV p24 antigen in the brain lysates by RT-PCR. 


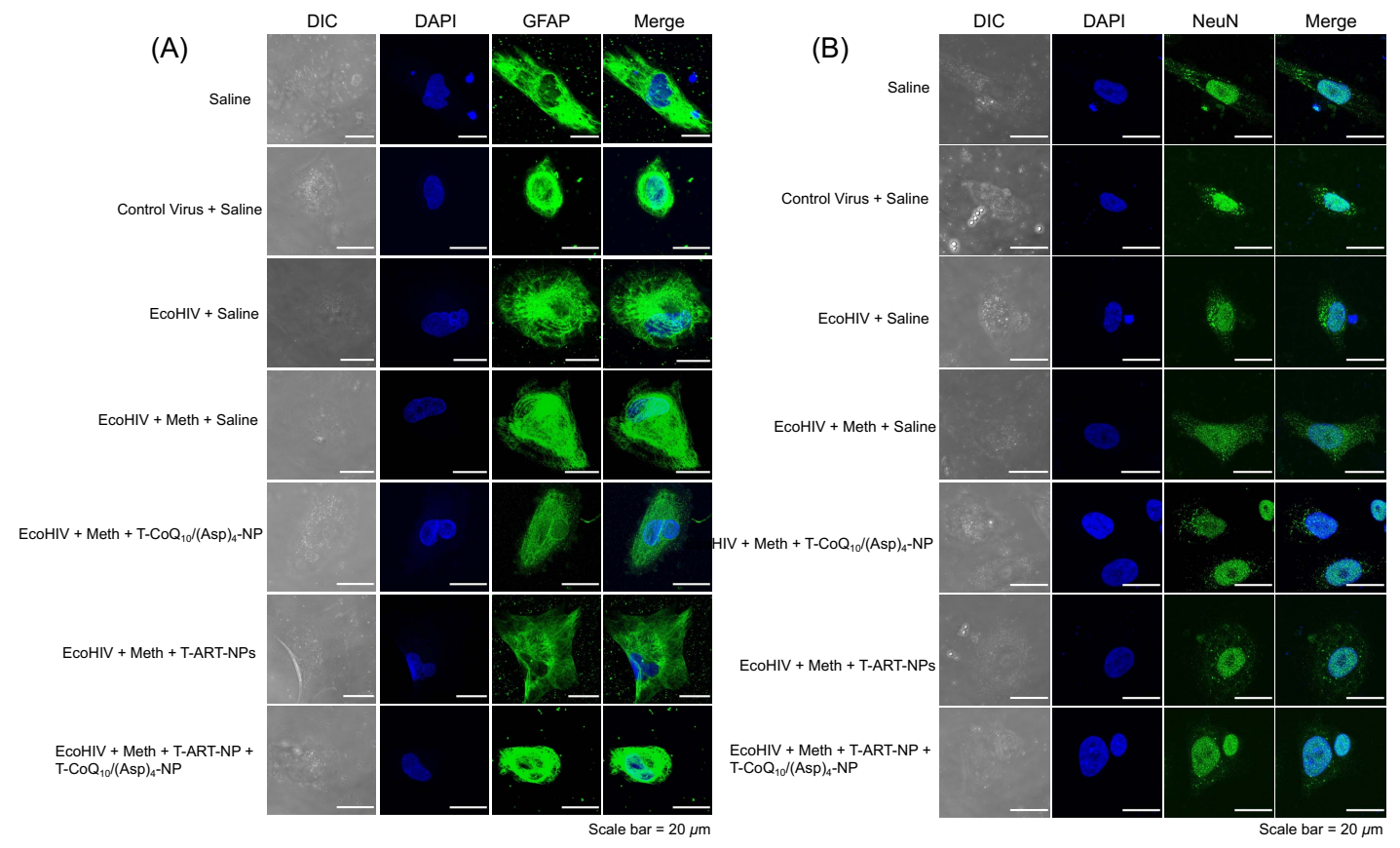

Figure S9: Expression of GFAP in isolated astrocytes and NeuN in isolated neurons by immunostaining method. 


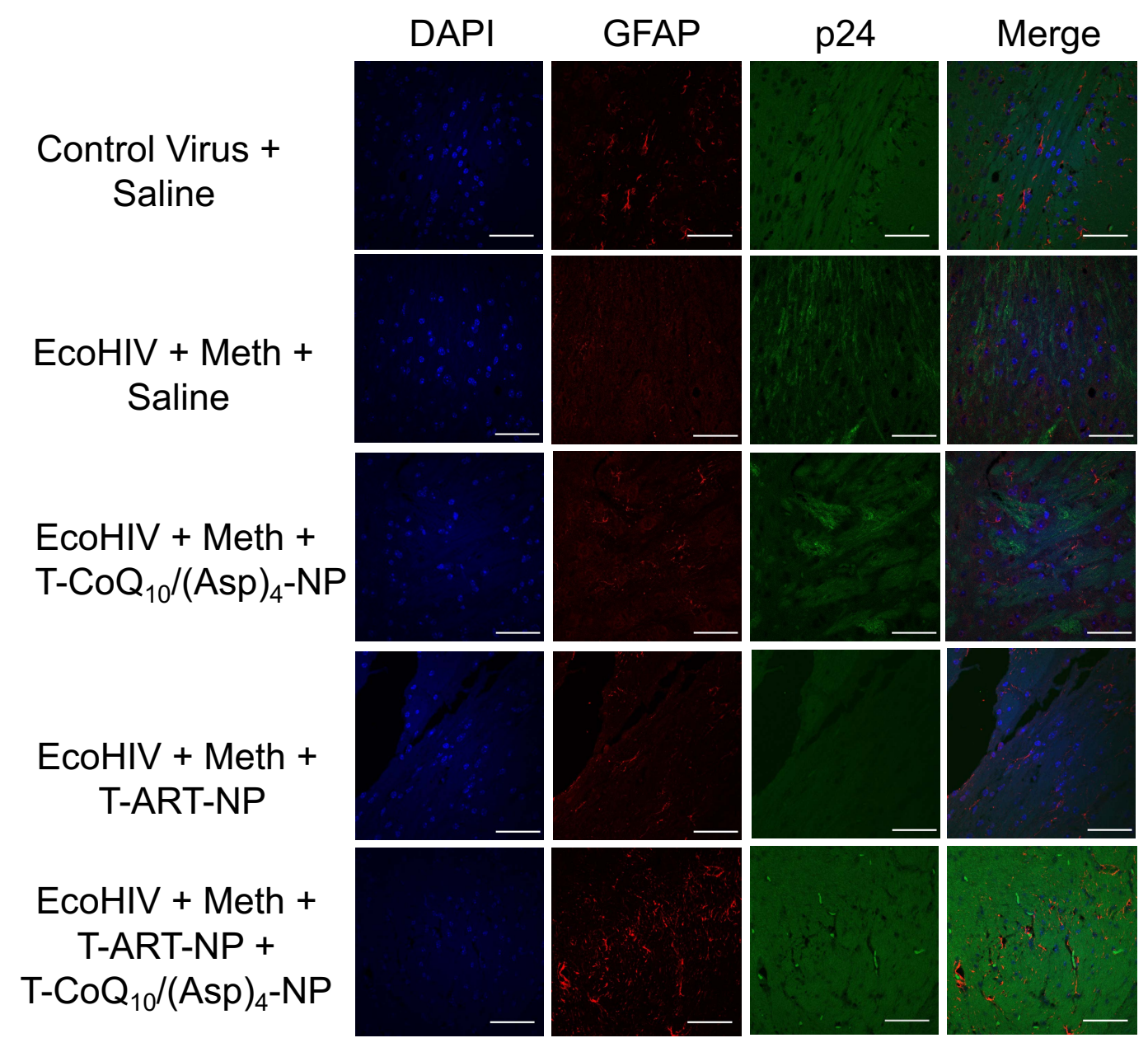

Figure S10. Immunofluorescence images of brain tissues stained for p24 viral protein along with GFAP for astrocytes. C57BL/6 male mice were divided into 12 groups and were assigned to the following treatment groups: control virus + Meth + saline (12 animals); control virus + saline (12 animals); control virus + Meth + T-CoQ $10-\mathrm{NP} / \mathrm{T}-(\mathrm{Asp})_{4}-\mathrm{NP}(13$ animals); EcoHIV + Meth + saline (11 animals); EcoHIV + Meth + T-CoQ $10-N P / T-(A s p){ }_{4}-N P(10$ animals); EcoHIV + Meth + T-ARTNPs (12 animals); EcoHIV + Meth + T-ART-NP + T-CoQ $10-N P / T-(A s p)_{4}-N P$ (16 animals); control Virus + Meth + T-CoQ $10 /($ Asp) 4 -NPs (11 animals); control Virus + T-ART-NPs (13 animals); control Virus + T-ART-NPs + T-CoQ ${ }_{10} /(\text { Asp })_{4}-\mathrm{NPs}$ (12 animals), saline (3 animals), and EcoHIV + saline ( 3 animals). The mice were treated with either control virus (pBMN-I-GFP) or chimeric HIV-NDK (EcoHIV, $1 \mu \mathrm{g}$ of p24), followed by one-week multiday exposure to Meth $(0.2 \mathrm{mg} / \mathrm{kg}$ at each injection for 5 days) and subsequent two-week treatment with T-ART-NPs $(5 \mathrm{mg} / \mathrm{kg}$ with respect to the drug) and T-CoQ $10 /(\text { Asp })_{4}-\mathrm{NPs}(20 \mathrm{mg} / \mathrm{kg}$ with respect to the drug) via intravenous route. Scale bar $=50 \mu \mathrm{m}$. 


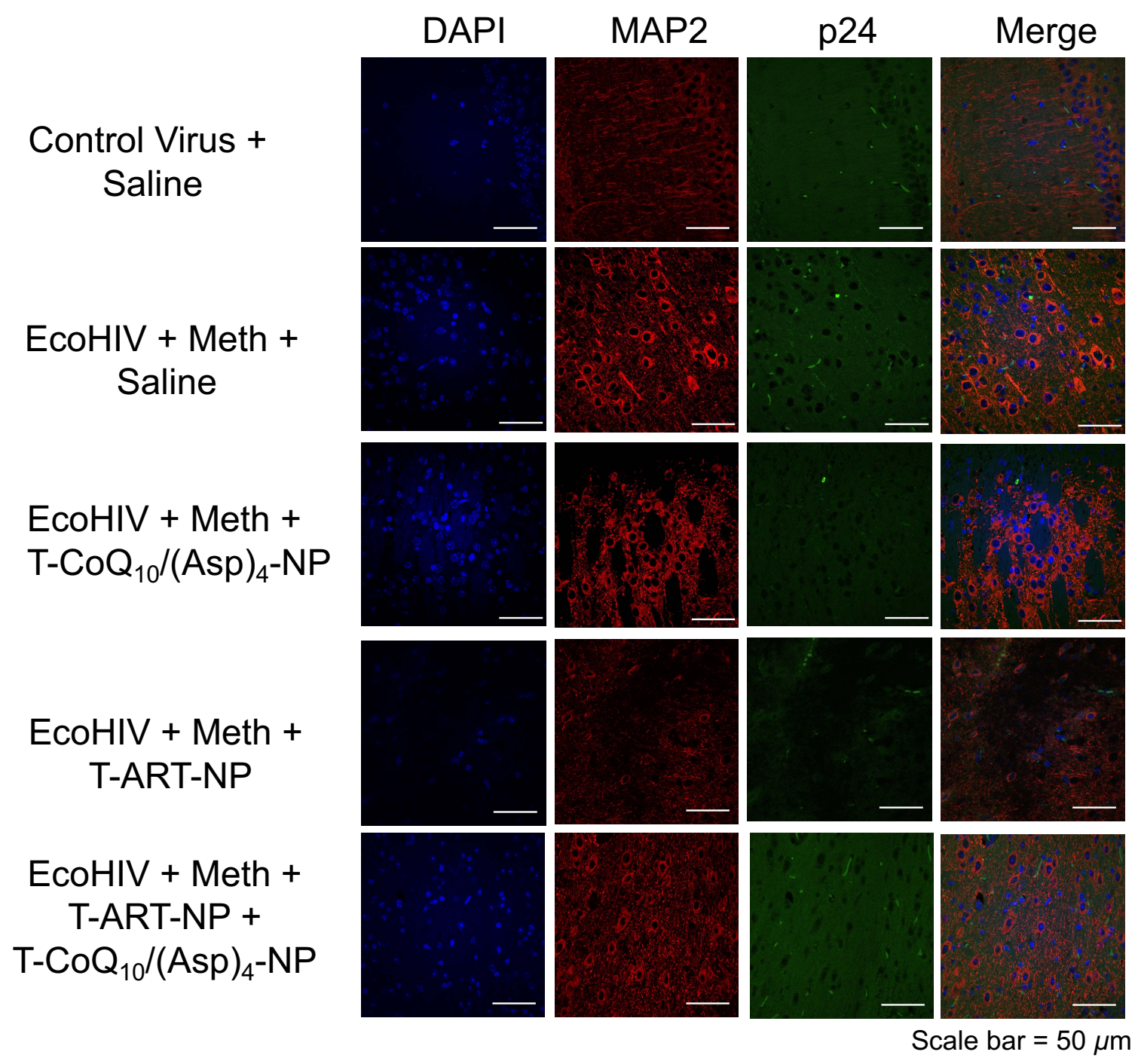

Figure S11. Immunofluorescence images of brain tissues stained for p24 viral protein along with MAP2 for neurons. C57BL/6 male mice were divided into 12 groups and were assigned to the following treatment groups: control virus + Meth + saline (12 animals); control virus + saline (12 animals); control virus + Meth + T-CoQ $10-N P / T-(A s p)_{4}-\mathrm{NP}$ (13 animals); EcoHIV + Meth + saline (11 animals); EcoHIV + Meth + T-CoQ $10-N P / T-(A s p)_{4}-\mathrm{NP}$ (10 animals); EcoHIV + Meth + T-ART-NPs (12 animals); EcoHIV + Meth + T-ART-NP + T-CoQ10-NP/T-(Asp)4-NP (16 animals); control Virus + Meth + T-CoQ $10 /(\text { Asp) })_{4}-N P s$ (11 animals); control Virus + T-ART-NPs (13 animals); control Virus + T-ART-NPs + T-CoQ ${ }_{10} /(\text { Asp })_{4}-\mathrm{NPs}$ (12 animals), saline (3 animals), and EcoHIV + saline ( 3 animals). The mice were treated with either control virus (pBMN-I-GFP) or chimeric HIV-NDK (EcoHIV, $1 \mu \mathrm{g}$ of p24), followed by one-week multiday exposure to Meth $(0.2 \mathrm{mg} / \mathrm{kg}$ at each injection for 5 days) and subsequent two-week treatment with T-ART-NPs (5 $\mathrm{mg} / \mathrm{kg}$ with respect to the $\mathrm{drug}$ ) and T-CoQ ${ }_{10} /(\mathrm{Asp})_{4}-\mathrm{NPs}(20 \mathrm{mg} / \mathrm{kg}$ with respect to the drug) via intravenous route. 


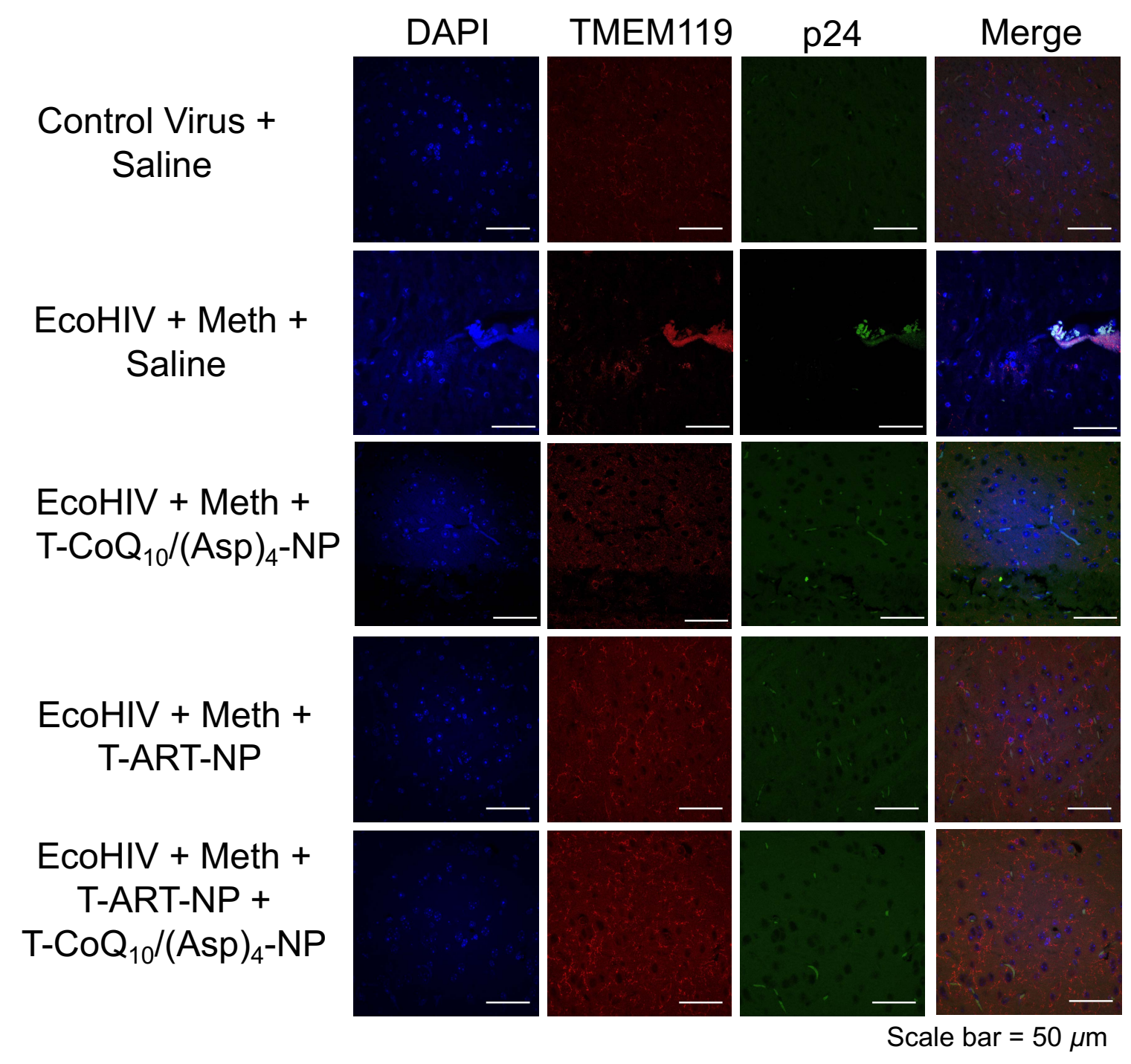

Figure S12. Immunofluorescence images of brain tissues stained for p24 viral protein along with TMEM119 for microglia. C57BL/6 male mice were divided into 12 groups and were assigned to the following treatment groups: control virus + Meth + saline (12 animals); control virus + saline (12 animals); control virus + Meth + T-CoQ ${ }_{10}-\mathrm{NP} / \mathrm{T}-(\mathrm{Asp})_{4}-\mathrm{NP}$ (13 animals); EcoHIV + Meth + saline (11 animals); EcoHIV + Meth + T-CoQ $10-N P / T-(A s p) 4-N P$ (10 animals); EcoHIV + Meth + T-ART-NPs (12 animals); EcoHIV + Meth + T-ART-NP + T-CoQ $10-N P / T-(A s p)_{4}-N P$ (16 animals); control Virus + Meth + T-CoQ $10 /(\text { Asp })_{4}-N P s$ (11 animals); control Virus + T-ART-NPs (13 animals); control Virus + T-ART-NPs + T-CoQ ${ }_{10} /(\text { Asp })_{4}-N P s$ (12 animals), saline (3 animals), and EcoHIV + saline (3 animals). The mice were treated with either control virus (pBMN-I-GFP) or chimeric HIV-NDK (EcoHIV, $1 \mu \mathrm{g}$ of p24), followed by one-week multiday exposure to Meth $(0.2 \mathrm{mg} / \mathrm{kg}$ at each injection for 5 days) and subsequent two-week treatment with T-ART-NPs (5 $\mathrm{mg} / \mathrm{kg}$ with respect to the drug) and T-CoQ ${ }_{10} /(\mathrm{Asp})_{4}-\mathrm{NPs}(20 \mathrm{mg} / \mathrm{kg}$ with respect to the drug) via intravenous route. 


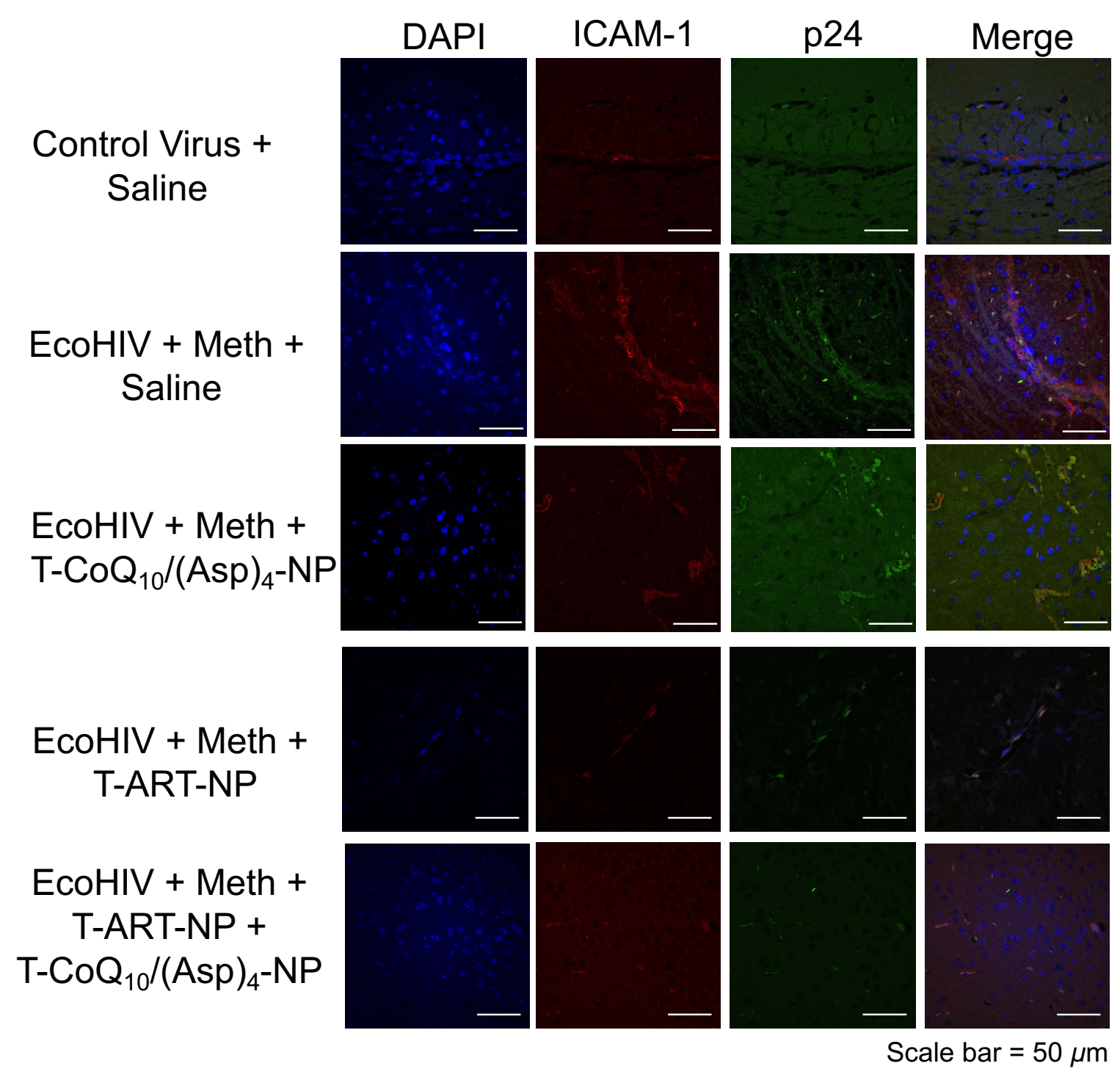

Figure S13. Immunofluorescence images of brain tissues stained for p24 viral protein along with ICAM-1 for neuroinflammation. C57BL/6 male mice were divided into 12 groups and were assigned to the following treatment groups: control virus + Meth + saline (12 animals); control virus + saline (12 animals); control virus + Meth + T-CoQ ${ }_{10}-\mathrm{NP} / \mathrm{T}-(\mathrm{Asp})_{4}-\mathrm{NP}$ (13 animals); EcoHIV + Meth + saline (11 animals); EcoHIV + Meth + T-CoQ $10-N P / T-(A s p)_{4}-N P$ (10 animals); EcoHIV + Meth + T-ART-NPs (12 animals); EcoHIV + Meth + T-ART-NP + T-CoQ $10-N P / T-(\text { Asp })_{4}-$ NP (16 animals); control Virus + Meth + T-CoQ $10 /(\text { Asp) })_{4}-N P s$ (11 animals); control Virus + TART-NPs (13 animals); control Virus + T-ART-NPs + T-CoQ ${ }_{10} /(\text { Asp })_{4}-N P s$ (12 animals), saline (3 animals), and EcoHIV + saline (3 animals). The mice were treated with either control virus (pBMN-I-GFP) or chimeric HIV-NDK (EcoHIV, $1 \mu \mathrm{g}$ of p24), followed by one-week multiday exposure to Meth $(0.2 \mathrm{mg} / \mathrm{kg}$ at each injection for 5 days) and subsequent two-week treatment with T-ART-NPs (5 mg/kg with respect to the drug) and T-CoQ ${ }_{10} /(\mathrm{Asp})_{4}-\mathrm{NPs}(20 \mathrm{mg} / \mathrm{kg}$ with respect to the drug) via intravenous route. 


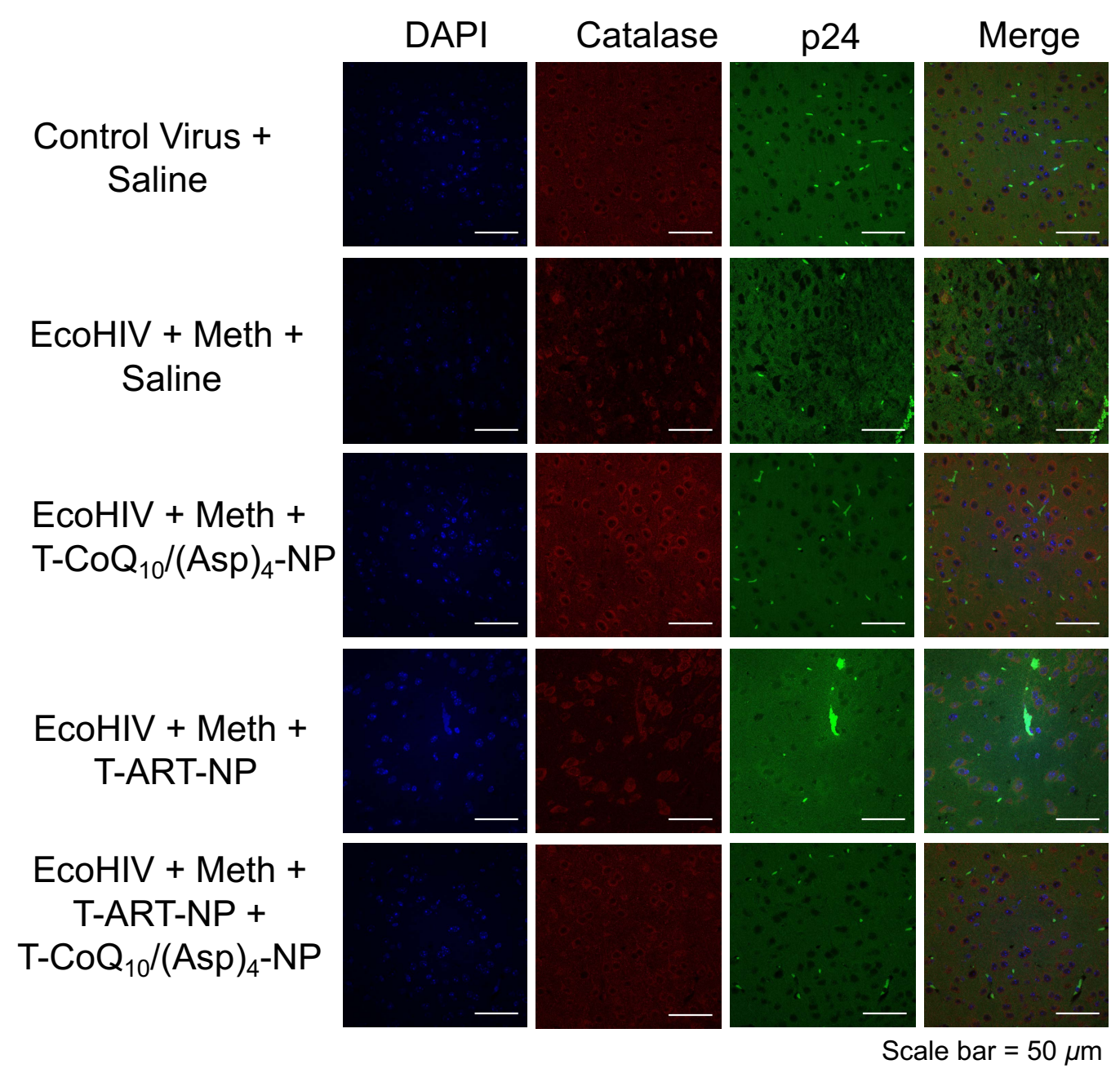

Figure S14. Immunofluorescence images of brain tissues stained for $\mathrm{p} 24$ viral protein along with catalase for ROS marker. C57BL/6 male mice were divided into 12 groups and were assigned to the following treatment groups: control virus + Meth + saline (12 animals); control virus + saline (12 animals); control virus + Meth + T-CoQ $10-N P / T-(A s p)_{4}-\mathrm{NP}$ (13 animals); EcoHIV + Meth + saline (11 animals); EcoHIV + Meth + T-CoQ ${ }_{10}-\mathrm{NP} / \mathrm{T}-(\mathrm{Asp}){ }_{4}-\mathrm{NP}(10$ animals); EcoHIV + Meth + T-ART-NPs (12 animals); EcoHIV + Meth + T-ART-NP + T-CoQ ${ }_{10}-\mathrm{NP} / \mathrm{T}-(\mathrm{Asp})_{4}-\mathrm{NP}$ (16 animals); control Virus + Meth + T-CoQ $10 /($ Asp) 4 -NPs (11 animals); control Virus + T-ART-NPs (13 animals); control Virus + T-ART-NPs + T-CoQ $10 /($ Asp) 4 -NPs (12 animals), saline (3 animals), and EcoHIV + saline ( 3 animals). The mice were treated with either control virus (pBMN-I-GFP) or chimeric HIV-NDK (EcoHIV, $1 \mu \mathrm{g}$ of p24), followed by one-week multiday exposure to Meth $(0.2 \mathrm{mg} / \mathrm{kg}$ at each injection for 5 days) and subsequent two-week treatment with T-ART-NPs (5 $\mathrm{mg} / \mathrm{kg}$ with respect to the drug) and T-CoQ ${ }_{10} /(\mathrm{Asp})_{4}-\mathrm{NPs}(20 \mathrm{mg} / \mathrm{kg}$ with respect to the drug) via intravenous route. 


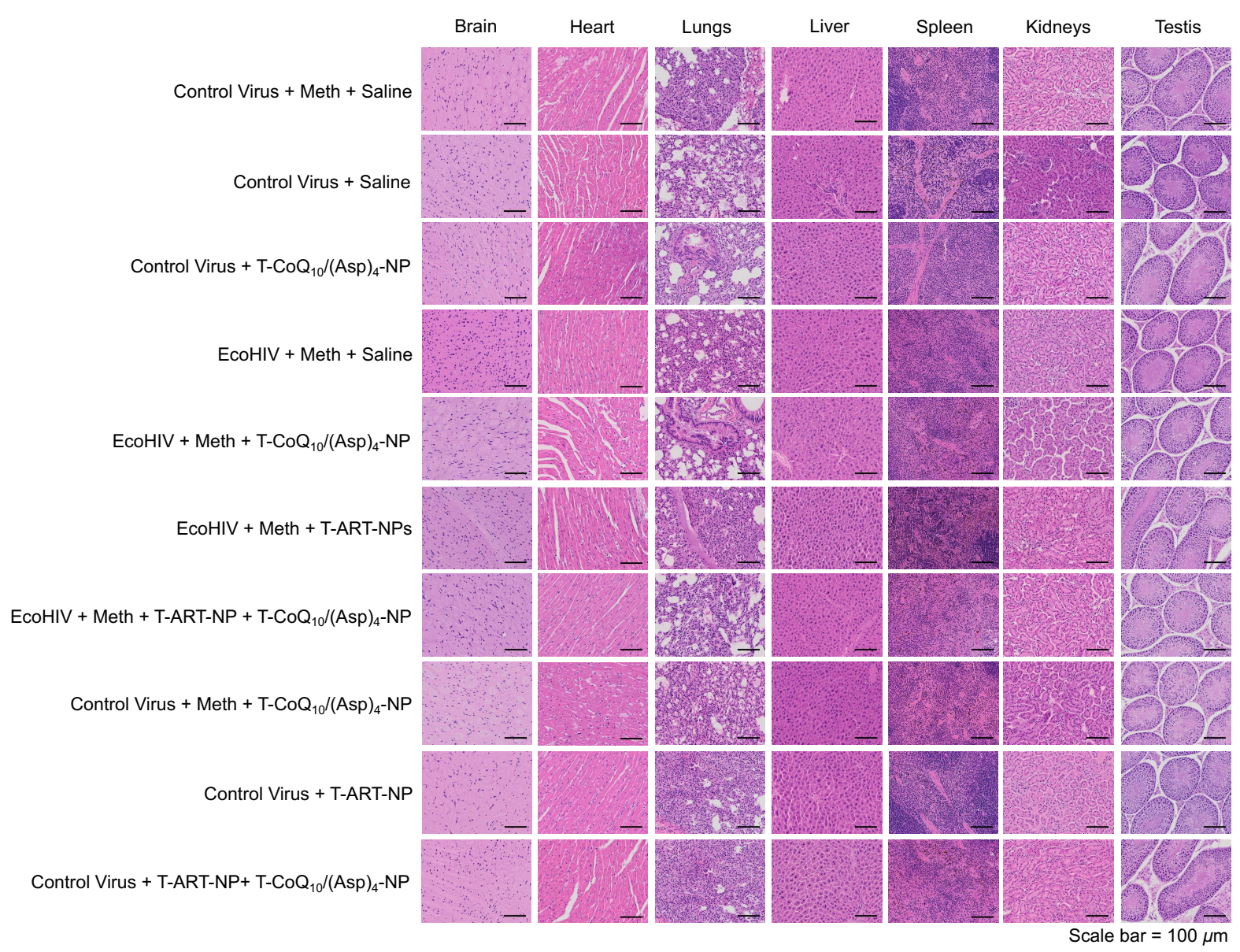

Figure S15. H\&E images of all the tissue sections after the treatment (Scale bar $=50 \mu \mathrm{m}$ ). C57BL/6 male mice were divided into 12 groups and were assigned to the following treatment groups: control virus + Meth + saline (12 animals); control virus + saline (12 animals); control virus + Meth + T-CoQ $10-\mathrm{NP} / \mathrm{T}-(\mathrm{Asp})_{4}-\mathrm{NP}$ (13 animals); EcoHIV + Meth + saline (11 animals); EcoHIV + Meth + T-CoQ $10-N P / T-(A s p)_{4}-N P(10$ animals); EcoHIV + Meth + T-ART-NPs (12 animals); EcoHIV + Meth + T-ART-NP + T-CoQ ${ }_{10}-\mathrm{NP} / \mathrm{T}-\left(\right.$ Asp) ${ }_{4}-\mathrm{NP}$ (16 animals); control Virus + Meth + T-CoQ ${ }_{10} /(\text { Asp })_{4}$-NPs (11 animals); control Virus + T-ART-NPs (13 animals); control Virus + T-ART-NPs + T-CoQ ${ }_{10} /(\text { Asp })_{4}$-NPs (12 animals), saline (3 animals), and EcoHIV + saline (3 animals). The mice were treated with either control virus (pBMN-I-GFP) or chimeric HIV-NDK (EcoHIV, $1 \mu \mathrm{g}$ of p24), followed by one-week multiday exposure to Meth $(0.2 \mathrm{mg} / \mathrm{kg}$ at each injection for 5 days) and subsequent two-week treatment with T-ART-NPs ( $5 \mathrm{mg} / \mathrm{kg}$ with respect to the drug) and T-CoQ ${ }_{10} /(\mathrm{Asp})_{4}-\mathrm{NPs}(20 \mathrm{mg} / \mathrm{kg}$ with respect to the drug) via intravenous route. 


\section{References}

1. Marrache, S.; Pathak, R. K.; Dhar, S., Detouring of Cisplatin to Access Mitochondrial Genome for Overcoming Resistance. Proc. Natl. Acad. Sci. U. S. A. 2014, 10444-10449.

2. Kalathil, A. A.; Kumar, A.; Banik, B.; Ruiter, T. A.; Pathak, R. K.; Dhar, S., New Formulation of Old Aspirin for Better Delivery. Chem. Commun. 2016, 140-143.

3. Samikkannu, T.; Atluri, V. S.; Nair, M. P., HIV and Cocaine Impact Glial Metabolism: Energy Sensor AMP-activated protein kinase Role in Mitochondrial Biogenesis and Epigenetic Remodeling. Sci Rep 2016, 31784.

4. Samikkannu, T.; Rao, K. V.; Ding, H.; Agudelo, M.; Raymond, A. D.; Yoo, C.; Nair, M. P., Immunopathogenesis of HIV Infection in Cocaine Users: Role of Arachidonic Acid. PLoS One 2014, e106348.

5. Geraghty, P.; Hadas, E.; Kim, B.-H.; Dabo, A. J.; Volsky, D. J.; Foronjy, R., HIV Infection Model of Chronic Obstructive Pulmonary Disease in Mice. Am. J. Physiol. Lung Cell Mol. Physiol. 2017, L500L509. 